\title{
Electrospun Nanofibers for Wound Dressing and Tissue Engineering Applications
}

\section{Yara Örtüsü ve Doku Mühendisliği Uygulamaları için Elektro-eğirme ile Üretilen Nanolifler}

\section{Brabu Balusamy ${ }^{\bullet}$, Anitha Senthamizhan ${ }^{\circledR}$ and Tamer Uyar*๑}

Department of Fiber Science \& Apparel Design, College of Human Ecology, Cornell University, Ithaca, NY 14853, USA.

\section{ABSTRACT}

- lectrospinning has received tremendous attention in the fabrication of nanofibrous scaffolds over recent years and - employed in different biomedical applications because of their biomimetic nature. Especially, the electrospun nanofibers exhibit several beneficial features including natural extracellular matrix (ECM), interconnected pores, large surface area, ease of functionalization and mechanical performance that holds huge importance in influencing the cell adhesion, differentiation and proliferation behaviour. To date, acknowledging the wide range of beneficial features, the electrospun nanofibers have been used in wound dressing and tissue engineering applications. This review summarizes various efforts have been made in these areas with several representative examples indicating use of various materials and approaches. Further the concerns for future direction regard to clinical phase transfer has been discussed.

\section{Key Words}

Electrospinning, nanofibers, wound dressing, Tissue engineering.

\section{öz}

— lektro-eğirme yöntemi ile üretilen nanolifler, son yıllarda nanofibröz yapı iskelelerinin geliştirilmesinde büyük ilgi — gördü ve biyomimetik yapıları nedeniyle farklı biyomedikal uygulamalarda kullanıldı. Özellikle, elektro-eğirme yöntemi ile üretilen nanolifler doğal hücre dışı matris (ECM), birbirine bağlı gözenekler, geniş yüzey alanı, işlevselleştirme kolaylığı ve hücre adezyonunu, farklılaşmasını ve proliferasyon davranışını etkilemede büyük önem taşıyan mekanik performans dahil olmak üzere birçok faydalı özellik sergiler. Bugüne kadar, çok çeşitli yararlı özellikleri kabul eden bu nanolifler, yara örtüsü ve doku mühendisliği uygulamalarında kullanıımıştır. Bu derlemede, çeşitli malzemelerin ve yaklaşımların kullanımını gösteren birkaç temsili örneklerle bu alanlarda çeşitli çabaların yapıldığını özetlemektedir. Ayrıca, klinik faz transferine ilişkin gelecekteki yön endişeleri tartışılmıştır.

\section{Anahtar Kelimeler}

Elektro-eğirme, nanolif, yara örtüsü, doku mühendisliği.

Article History: Received: Sep 01, 2020; Revised: Sep 20, 2020; Accepted: Oct 20, 2020; Available Online: Oct $20,2020$. DOI: https://doi.org/10.15671/hjbc.789186

Correspondence to: T. Uyar, Department of Fiber Science \& Apparel Design, College of Human Ecology, Cornell University, Ithaca, NY 14853, USA. E-Mail: tu46@cornell.edu 


\section{INTRODUCTION}

- lectrospinning has received tremendous attenti— on in the fabrication of fibers at various diameters from numerous materials and recognized as most feasible and economical approach in the recent decades. A syringe pump, needle spinneret, high-voltage power supply and grounded collector are the primary components of the basic electrospinning setup that adopts electrohydrodynamic process in which a liquid is injected under a strong electric field to generate a jet that has been further stretched and elongated in the electric field followed by deposition on a grounded collector as fibers. The history of electrospinning can be tracked back from 18th century, however the technique has been well established in the recent decades [1-6]. Inspired by the potential features of electrospinning, several types of electrospinning including melt electrospinning, needleless electrospinning, coaxial electrospinning, emulsion electrospinning, multi-hole electrospinning, multi-jet electrospinning, gas-assisted/gas jet electrospinning (electroblowing), centrifugal electrospinning and near-field electrospinning has been developed [7]. Figure 1 represents the schematic illustrations of electrospinning, spinneret types, fibrous morphology, collectors, solution and process parameters influencing the fiber fabrication [8]. The electrospun fibers offer several beneficial characteristics including versatile composition, diverse morphology, tunable diameter, easy functionalization of active molecules, higher surface area, control over alignment, interconnectivity, porous nature, mechanical stability, easy handling and possibility of scale-up production $[3,5,6,8]$.

Owing to the potential beneficial features, the electrospun nanofibers have been enormously employed in various sectors including energy [9-13], environmental [9,10-12,14-28] and biomedical [9,12,29-44] applications. Especially, appreciable efforts have been paved towards designing and development of various elect-

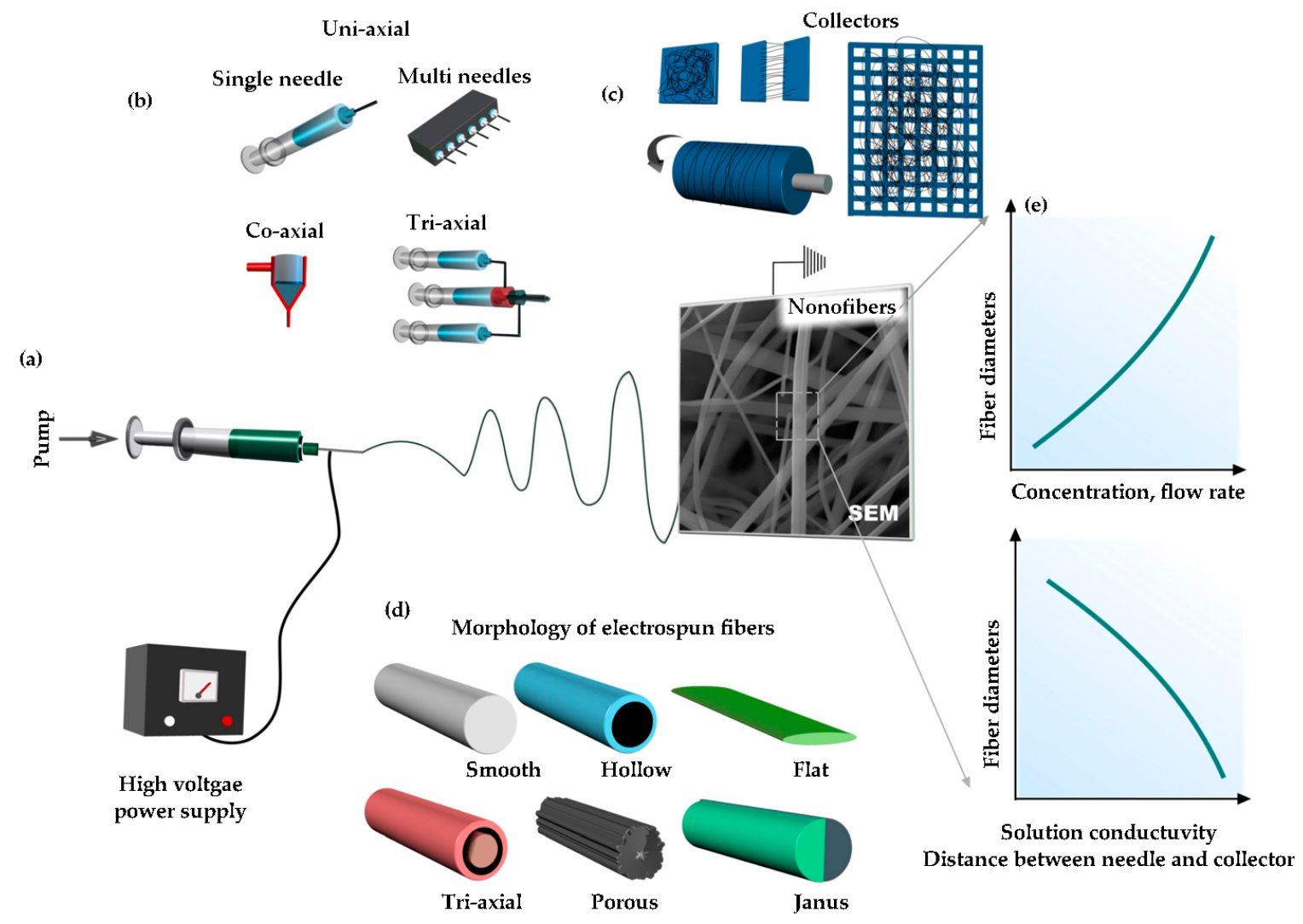

Figure 1. An electrospinning setup with important parameters is shown. (a) A cartoon scheme of an electrospinning system with the scanning electron micrograph of electrospun fibers, (b) common spinneret systems used in electrospinning, (c) collector types, (d) the morphology of electrospun fibers, and (e) diagrams showing the influence of electrospinning process parameters and solution properties on the electrospun fibers. Reprinted from [8] 2019 MDPI. 
rospun nanofibers for wound healing and tissue engineering applications that brought the fields a step forward [31,34,42,44-50]. In a depth view of biomedicine perspective, the electrospun nanofibers holds several beneficial characteristics that potentially credit their use especially in wound healing and tissue engineering applications. On a particular note, any materials that intended for wound healing and tissue engineering applications must mimic natural extracellular matrix (ECM) in terms of their mechanical and functional features, that plays critical role in the attachment, differentiation and proliferation of cells, thereby serves as a structural support for new tissues. The natural ECM comprised of several components including collagen, laminin, structural protein, fibronectin, elastin, hyaluronan, proteoglycan and glycoprotein those exhibit different roles such as flexibility, growth factor stabilization, regulation of adhesion and signaling between ECM and cells [51]. In this context, development of scaffolds mimicking the ECM structural characteristics is of great challenge for the wound healing and tissue engineering applications. Certainly, the electrospun nanofibers have been significantly improved the scope of scaffold fabrication and vastly demonstrated their potential in wound healing and various tissue engineering applications. On a short note, the possibility in easy coordination of the parameters enable excellent tuning of electrospun nanofibrous architecture to mimic the ECM structural dimensions ex vivo with large surface area along with high porosity and encapsulated with numerous components that greatly supports the cell binding and proliferation [46]. Although electrospun nanofibers can be produced from several natural and synthetic polymeric origins, encapsulation of various active agents greatly benefits enhanced wound healing and tissue engineering processes. Especially, the electrospinning approach offers feasible opportunities to incorporate active molecules using different strategies, mainly through direct blending, coreshell and surface grafting. In this review, we provide an update on the variety of approaches and materials used in the fabrication of electrospun nanofibers intended for wound dressing and tissue engineering applications. Further, several representative examples are introduced and discussed in order to demonstrate significant advances in the progress of developing such electrospun nanofibers for intended applications. Finally, associated challenges in the fabrication of electrospun nanofibers for biomedical applications are discussed and an outlook on the future prospectus is presented.

\section{ELECTROSPUN NANOFIBERS for WOUND DRESSING and TISSUE ENGINEERING APPLICATIONS}

\section{Electrospun Nanofibers in Wound Dressing Application}

Skin have known as a largest organ of the human body with an area of $\sim 2 \mathrm{~m}^{2}$ which has three different layers such as epidermis, dermis, and hypodermis. The skin act as a protection barrier for internal tissues from mechanical damage, dehydration, UV radiation, extreme temperature and microbial invasion. Furthermore, the skin also helps in the regulation of body temperature, sensory detection process and immune system [52-54]. The wounds can be defined as any injuries or disruption of the epidermis layer of the skin caused by various factors including physical, chemical or thermal agents that may results in further damages to muscles, tissues and nerves, thereby interruption of normal physiological functions of the skin. The wounds are primarily classified into acute and chronic wounds based on their time of healing nature. The acute wounds are tends to heal in fixed time period generally within four weeks, whereas the healing process in the chronic wounds is not predictable. It's worth to highlight that, several factors including infection, inflammation and fluid loss in the acute wounds delays the healing process that may results in the emergence of chronic wounds. Therefore, fast regeneration of injured skin limits the complications of transferring to chronic wounds [55-57]. The wound healing process generally initiated as soon as followed by any injuries to the skin in order to stop the bleeding by deposition of fibrinogen to initiate the clot and reestablish the tissue architecture. In this context, numerous inflammatory cells, chemokines, cytokines, matrix molecules and nutrients are involved in the wound healing process. Briefly, the wound healing is a dynamic wellregulated process with consecutive phases including haemostasis, inflammation, cell proliferation and tissue remodeling $[44,55,56]$. Figure 2 depicts the mechanism and components involved in the wound healing process [58]. Although wound care management have known for centuries, it has been advanced in the recent decades.

The wound dressing materials are crucial factor in wound care management as it plays significant roles. An ideal wound dressing material should possess several features including moisture control in the wound, good gas permeation, mechanical protection, excess exu- 

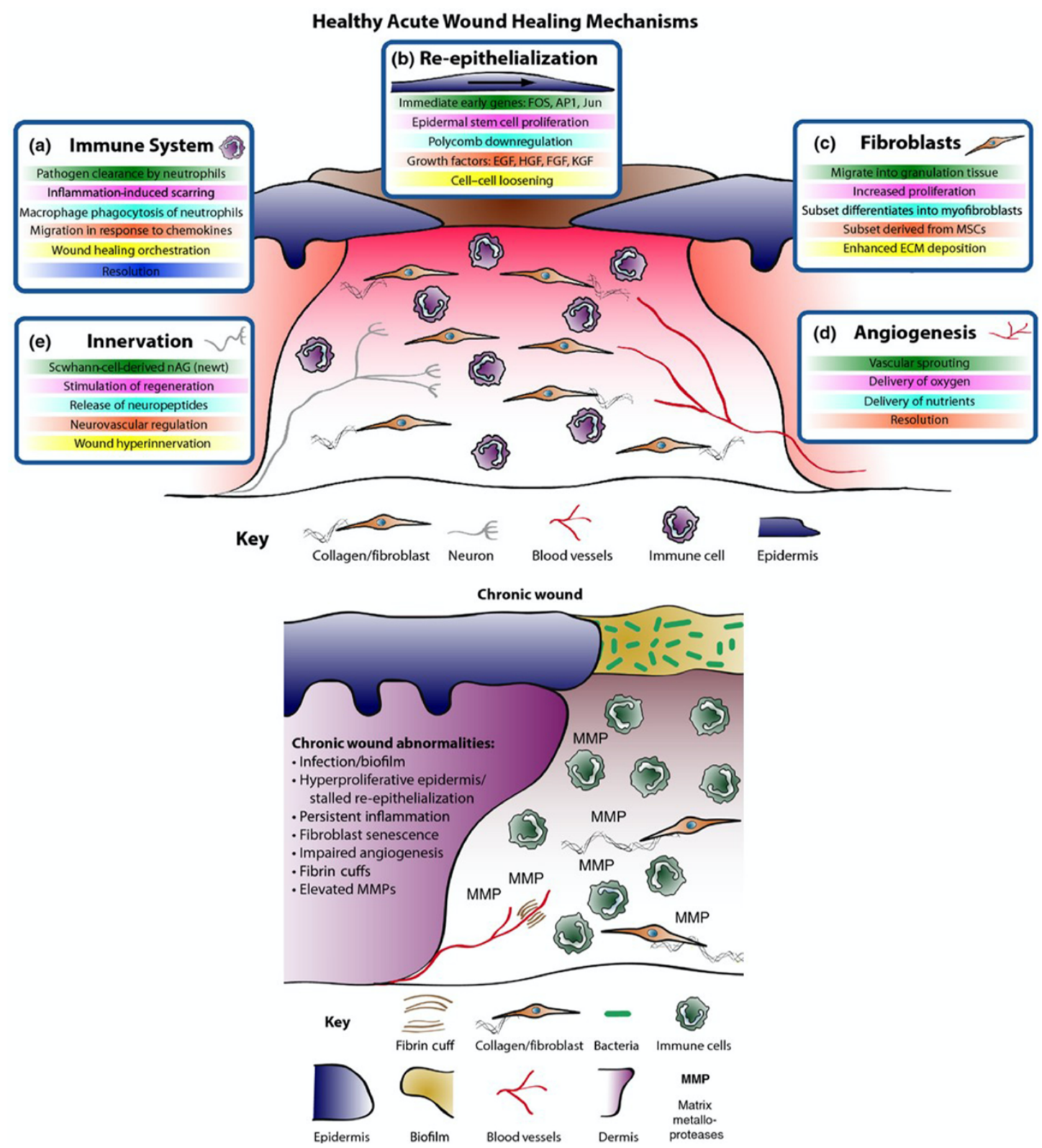

Figure 2. Acute wound healing mechanisms. The healing of an acute wound involves coordinated cellular and molecular responses. (a) Initially immune cells migrate to the wound site and, in addition to clearing invading pathogens, in part they also orchestrate the healing process. (b) Cut epidermal edges upregulate wound-associated genes, thus enabling collective cell migration. (c) Local and blood-borne fibroblasts proliferate and migrate to form the wound granulation tissue, provide structure and signalling cues and deposit new extracellular matrix (ECM). Some fibroblasts differentiate into myofibroblasts to aid wound contraction. (d) The wound bed is perfused with oxygen and nutrients through new blood vessels derived by angiogenesis. (e) Wound healing rates exhibit a positive correlation with innervation, but hyperinnervation after wound closure could contribute to neuropathic pain. EGF, epidermal growth factor; HGF, hepatocyte growth factor; FGF, fibroblast growth factor; KGF, keratinocyte growth factor; MSC, mesenchymal stem cell; nAG, newt anterior gradient protein. Reprinted from [58] 2015 John Wiley and Sons. 
dates elimination, protect wound against microbial invasion and infection, biocompatible, relive pain, easily changeable and economically affordable $[52,59,60]$. Therefore, selection of appropriate wound dressing is more critical aspect in the perspective of wound care management. To date, various forms of wound dressing materials are available for wound care management including films, foams, hydrogels and sponges. As the electrospun nanofibers holds all the necessary characteristics that an ideal wound dressing material requires, therefore in recent years a new class of nanofibrous wound dressing material have emerged with distinct features. In this regard, enormous progress has been made in the fabrication of electrospun nanofibers from variety of synthetic polymers, natural polymers, composites and encapsulated with variety of active agents including antimicrobials and growth factors for enhanced wound healing.

\section{Synthetic Polymeric Nanofibers Based Wound Dressings}

Indeed, several synthetic polymeric nanofibers have been extensively explored for their potential as wound dressing material. The synthetic polymers have several beneficial characteristics for optimal production of nanofibers which includes variable molecular weights, light weight, biodegradable in nature and good strength with high elasticity. Therefore, electrospun nanofibers can be optimally produced from the synthetic polymers by using suitable molecular weight, altering their composition, crystallinity and copolymerization. In this regard, numerous synthetic polymers include polystyrene (PS), polyurethane (PU), poly(vinyl alcohol) (PVA), poly(lactic acid) (PLA), poly(lactic-co-glycolic acid) (PLGA), polycaprolactone (PCL), polyglycolic acid (PGA), poly(L-lactic acid) (PLLA) and polyethylene oxide (PEO) have been used for the fabrication of electrospun nanofibers for wound healing applications. Specifically, few synthetic polymers have been approved by US Food and Drug Administration (FDA) for their use in biomedical applications [61-63]. The synthetic polymeric nanofibers have always functionalized with various active agents for their application in enhanced wound healing.

To highlight specifically, the synthetic electrospun nanofibers have been incorporated with variety of active agents including nanoparticles [64], antioxidants [65], anti-inflammatory $[65,66]$, stem cells [67] and antimicrobial agents [68] for their application in wound healing.
In this context, a very recent study reported the fabrication of epidermal growth factor (EGF) loaded PVA electrospun nanofiber membranes through bioorthogonal approach in which 3,4-dihydroxyphenethylamine (DOPA) was incorporated into the active site of EGF that leads to excellent bonding between the PVA and EGF. The cell proliferation study conducted in the NIH3T3 cells showcased 1.47 times higher proliferation that suggesting that the PVA nanofibers loaded DOPA-EGF could be used as excellent wound dressing material [69]. Another study reported by Lee and Lee demonstrated the fabrication of electrospun nanofiber based bioactive and interactive wound-dressing materials using PVA, plant-derived palmarosa oil and phytoncide oil [70]. Following fabrication of the nanofibers via emulsion electrospinning, several important studies including water uptake, air/moisture vapor transport and antimicrobial efficacy have been performed to evaluate their potential for wound dressing applications. The antimicrobial studies of nanofibers containing palmarosa oil have shown excellent effects against Staphylococcus aureus and Candida albicans. Further, the nanofibers had reasonable levels of gas and moisture vapor permeability and good water uptake ability that may benefit good gas permeability and exudate absorption. The overall results indicated that the developed electrospun nanofibers could be employed as potential bioactive wounddressing materials [70]. Similarly, natural antimicrobial compound thymol (THY) incorporated mesoporous silicon dioxide SBA-15 had been encapsulated to PCL electrospun nanofibers for advanced wound dressing application [71]. The release study demonstrated half of the loaded THY has been released within $7 \mathrm{~h}$ and exhibited good antibacterial potential against Staphylococcus aureus which indicating their use in wound dressing applications [71]. Malafatti and co-workers showcased the preparation of PLA nanofibers containing silver sulfadiazine (SDZ) and hydrotalcite ([Mg-Al]-LDH) which intended for wound skin healing [72]. The kinetics studies revealed slow release of SDZ and also exhibited good inhibitory effects against Escherichia coli and Staphylococcus aureus. The biocompatible nature is a most important parameter for the materials intended for biological applications and their toxicity nature in any possible exposure state should be evaluated for their successful applications [73-78]. Therefore, the biocompatible studies conducted on the PLA nanofibers containing SDZ and [Mg-Al]-LDH has shown good biocompatible nature in the human HDFn cells. Together 
with good antibacterial performance and other results of the studies indicated the great significance for wound dressing applications [71].

In another representative study, Asiatic acid (AA) has been incorporated in the porous PLLA electrospun fibrous scaffold (AA-PL) and evaluated their performance in the diabetic wound healing application [79]. The AA is an active substance of Centella asiatica extracts and holds beneficial features in the promoting the gene expressions of different growth factors including transforming growth factor- $\beta$ (TGF- $\beta$ ), vascular endothelial growth factor (VEGF) and fibroblast growth factors. The characterization studies confirmed the alignment of fi-
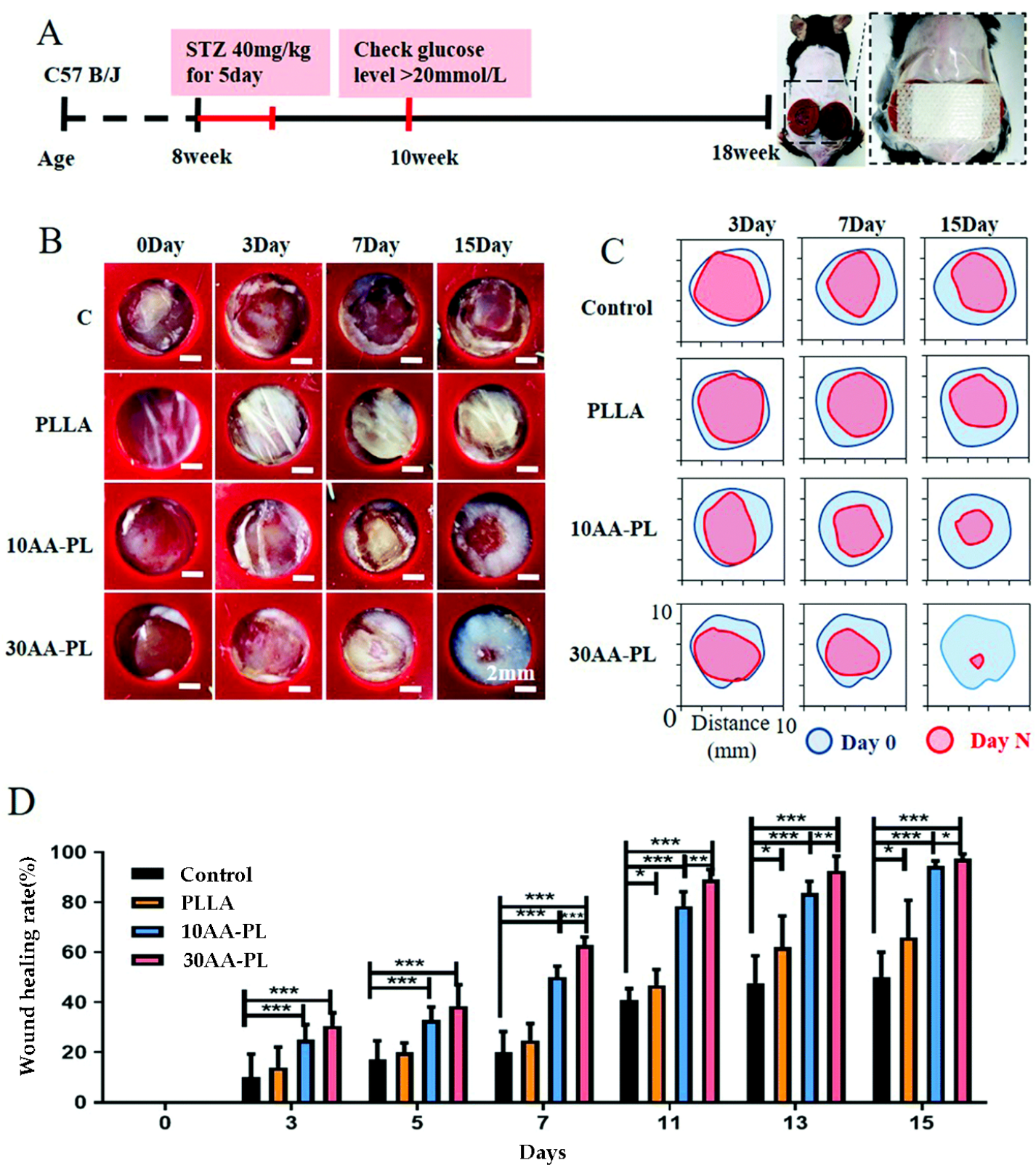

Figure 3. (A) Schematic diagram of the establishment of the non-contractile diabetic wound model. (B) Overview of the size change of the wounds in different groups (Ctrl, PLLA, $10 \mathrm{AA}-\mathrm{PL}, 30 \mathrm{AA}-\mathrm{PL}$ ) on days $0,3,7$ and 15 after surgery (scale bar $=2 \mathrm{~mm}$ ). (C) Wound trace for each treatment group on day $N$ (red area represents the wound area at day $N$, where $N=3,7$ and 15 ) after surgery relative to day 0 (blue area represents the wound area at day 0 ) in vivo. (D) Statistical analysis of the wound healing rate of PL-, $10 \mathrm{AA}-\mathrm{PL}-$, and 30 AA-PL-treated groups on days $0,3,5,7,11,13,15$ after surgery. $\left({ }^{*} P<0.05 ;{ }^{*} P<0.01 ;{ }^{* *} P<0.001\right)$. Reprinted with permission from [79] (C) 2019 The Royal Society of Chemistry. 
bers in a single direction with continuous release of the AA. The in vitro studies conducted in the $\mathrm{HaCat}$ cells and RAW 264.7 macrophage cells showcased an effective alleviation of $\mathrm{H}_{2} \mathrm{O}_{2}$-induced oxidative stress and down regulation of LPS-induced pro-inflammatory cytokine (IL-1 $\beta$, TNF- $\alpha$, IL6). In addition, the AA-PL fibrous scaffold exhibited good inhibition characteristics against Escherichia coli and Staphylococcus aureus. More specifically, the wound healing assay conducted in diabetic mice model resulted in excellent wound healing on day 15 by treating $30 \%$ AA incorporated scaffold (30 AA-PL) compared to $10 \%$ AA incorporated scaffold (10 AA-PL). Figure 3 depicts experimental procedure (Figure 3A) and wound healing performances (Figure 3B-D) in different treatment groups. In a depth analysis, the wounds treated with $30 \mathrm{AA}-\mathrm{PL}$ has shown $97.37 \%$ healing rate, whereas the $10 \mathrm{AA}-\mathrm{PL}$ groups have shown healing rate of $94.49 \%$. The outcome of the study suggested that the AA incorporated scaffolds could serve as an efficient material for the diabetic wound healing [79].

\section{Natural Polymeric Nanofibers Based Wound Dressings}

On the other hand, natural polymeric nanofibers have attracted fabulous attention in the wound dressing applications over synthetic polymers owing to their excellent biocompatibility, biodegradable nature, easy reorganization of cells for their physiological process, low antigenicity, enhanced interaction with components involved in healing process and environmental friendly nature. Therefore, vast attempts have been continuously being made on the exploring several natural polymeric materials including gelatin, collagen, cellulose, hyaluronic acid, fibrinogen, fibronectin, silk fibroin and alginate for their use in wound dressing application $[44,80,81]$. The natural polymeric materials can be processed without encapsulation of any active agents for the purpose of wound healing. In this context, fabrication of collagen electrospun nanofibers had been well demonstrated for biomedical applications. For instance, an early study reported by Matthews and co-workers demonstrated the fabrication of collagen nanofibers with tunable mechanical properties by controlling the fiber orientation [82]. Furthermore, the obtained collagen fibers found to promote cell growth and penetration of cells indicating their potential as scaffold for various regeneration and tissue engineering application [82]. In another effort, electrospun tilapia collagen nanofibers have been prepared for wound dressing applications [83]. The prepared collagen nanofibers have exhibited good tensile strength, contact angle, thermal stability and swelling characteristics. Further, the nanofibers demonstrated excellent proliferation of human keratinocytes (HaCaTs) and epidermal differentiation through up-regulated gene expressions of filaggrin, involucrin, and type I transglutaminase. In addition, excellent reepithelization of wound healing has been noted in the rat model. The cumulative outcome of the study indicated that the tilapia skin collagen nanofibers could be an ideal material for the wound healing application [83]. In similar trend, electrospun gelatin nanofibers have been also used for the wound healing applications because of their excellent biocompatible, air-permeability and haemostatic properties. Dias and co-workers demonstrated the fabrication of gelatin nanofibers and demonstrated their potential for wound dressing application [84]. In this study, in situ crosslinking of 1,4-butanediol diglycidyl ether (BDDGE) with different concentrations have optimized the fiber formation with well-defined fiber size, good mechanical properties and morphology. The evaluation studies performed to confirm their potentials in wound healing applications demonstrated good cell adhesion, proliferation and ECM synthesis with no significant toxicity in fibroblasts indicating their potential in wound dressing application [84].

In addition to the inherent beneficial characteristics of the natural polymers, incorporation of several active agents have showcased tremendous advancements in the enhanced wound healing. In this context, several antimicrobial agents including nanoparticles, plant extracts and growth factors have been incorporated in the natural polymeric nanofibers for enhanced wound healing applications. A representative study reported by Rath and co-workers demonstrated the incorporation of silver nanoparticles (AgNPs) into collagen nanofibers using electrospinning [85]. The resultant electrospun collagen nanofibers containing AgNPs have been systematically characterized for their morphology, release of silver ions and antibacterial potential. The results have shown that the obtained nanofibers had 300-700 nm diameter, sustained ion release with good antibacterial activity against Staphylococcus aureus and Pseudomonas aeruginosa. Further the wound healing performance evaluation conducted using an in vivo test model Wistar rats showed excellent results attributed to their intrinsic antibacterial, anti-inflammatory, hemostatic and controlled drug release profile properties [85]. Similarly, chitosan natural nanofibers have been surface functionalized with gentamicin-loaded liposome for the 
purpose of wound dressing applications [86]. The drug release kinetic studies have shown a sustained release of gentamicin during $16 \mathrm{~h}$ and reached a steady state at $24 \mathrm{~h}$ and the nanofibers exhibited excellent antibacterial potential against Escherichia coli, Pseudomonas aeruginosa and Staphylococcus aureus. Therefore, the overall study confirmed that the developed nanofibrous system could be applied as a promising wound dressing material [86]. As an example of functionalizing another natural polymeric nanofibrous system for wound dressing, Gallic acid (GA) has been loaded into cellulose acetate (CA) nanofibers through electrospinning and used further for their potential in wound dressing application [87]. For the purpose of comparison GA-loaded cellulose acetate films had been prepared. The results of studies conducted using transdermal diffusion through a pig skin method revealed that the nanofiber showed higher GA release, retained the anti-oxidant potential and exhibited antibacterial activity against Staphylococcus aureus indicating their potential for wound dressing material [87]. Comparably, silk fibroin has been also significantly explored for their potential use in wound dressing application. As an evident, a natural antioxidant fenugreek has been incorporated into silk fibroin nanofiber using co-electrospinning approach with different ratio [88]. The obtained nanofibers have been subjected to series of characterization and efficiency studies. The characterization studies revealed that the incorporation of fenugreek found to increase thermal and mechanical properties. In addition, the 1,1-diphenyl-2-picrylhydrazyl (DPPH) scavenging assay indicated increased anti-oxidant profile upon increasing concentration. The cell proliferation assay performed using Swiss albino $3 T 6$ cells at 48 and $72 \mathrm{~h}$ time period resulted in good cell proliferation, especially silk fibroin-fenugreek nanofibers at 1:0.1 revealed better spreading and adherence as illustrated in Figure 4. Further, the wound healing study performed in Wistar rats exhibited complete wound closure on day 16 and the histopathology studies revealed less inflammatory response with higher fibroblasts which implies their potential in accelerated wound healing [88].

\section{Composite Nanofibers Based Wound Dressings}

Although enormous efforts have been paved towards using either synthetic or natural polymeric nanofibrous systems for wound dressing applications, but still several limitations occur in several aspects including their mechanical strength, spinnability, encapsulation and release of active agents. Therefore, accountable progress has been made on the fabrication of composite fibers with synthetic-synthetic, natural-natural and synthetic-natural polymeric nanofibrous system, also incorporated with variety of active agents for enhanced wound dressing application. As a classic example in this regard, a recent study reported by Mehteroğlu and co-workers demonstrated the preparation of steviol glycosides based polyurethane/poly ( $\varepsilon$-caprolactone) (PU/PCL) fibers through electrospinning that intended for potential wound dressing material [89]. Briefly, the steviol glycosides has been first isolated from the stevia rebudiana as monomer followed by the synthesis
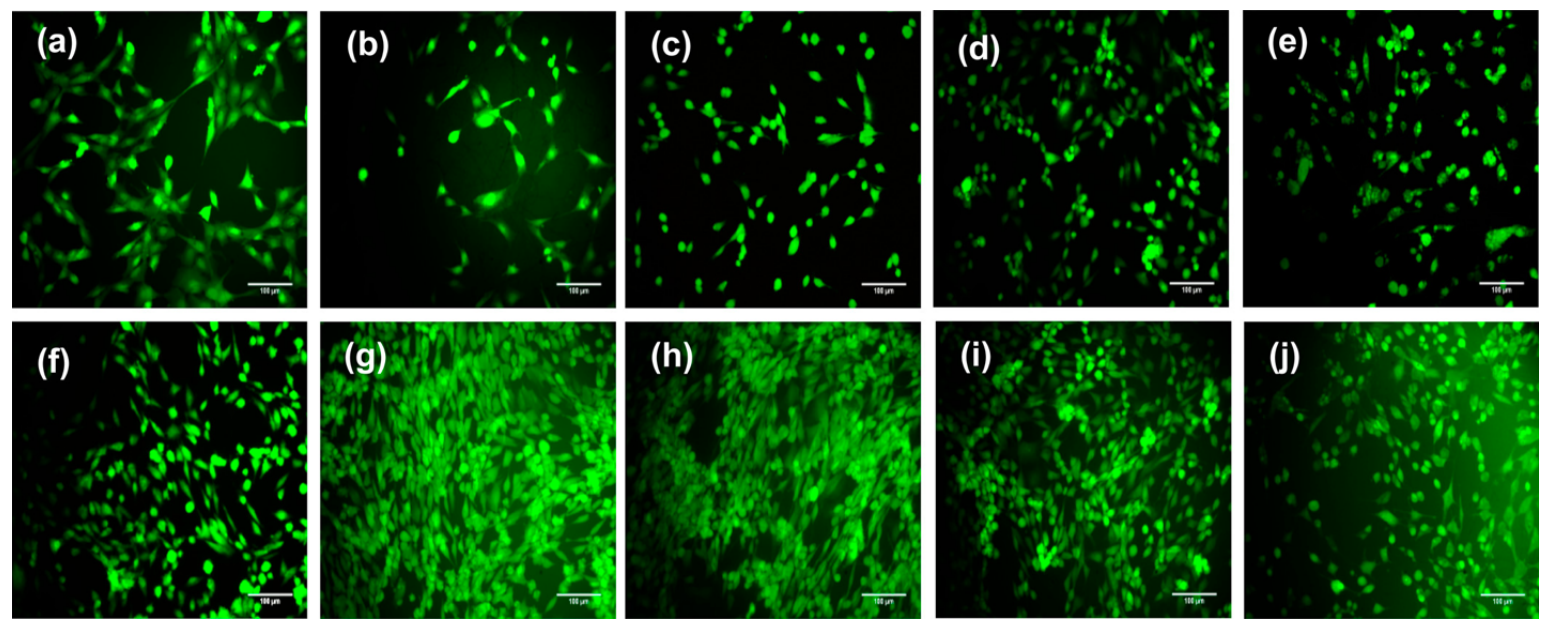

Figure 4. Proliferation of Swiss albino $3 T 6$ cells on nanofibrous scaffolds after different culture times determined by FDA staining $(a-e)$ after $48 \mathrm{~h},(f-j)$ after $72 \mathrm{~h}$ : (a,f) silk fibroin nanofibers, $(b, g)$ silk fibroin-fenugreek nanofibers (1:0.1), (c,h) silk fibroin-fenugreek nanofibers (1:0.2), (d,i) silk fibroin-fenugreek nanofibers (1:0.5), (e,j) silk fibroin-fenugreek nanofibers (1:1). Reprinted with permission from [88] (c) 2017 American Chemical Society. 

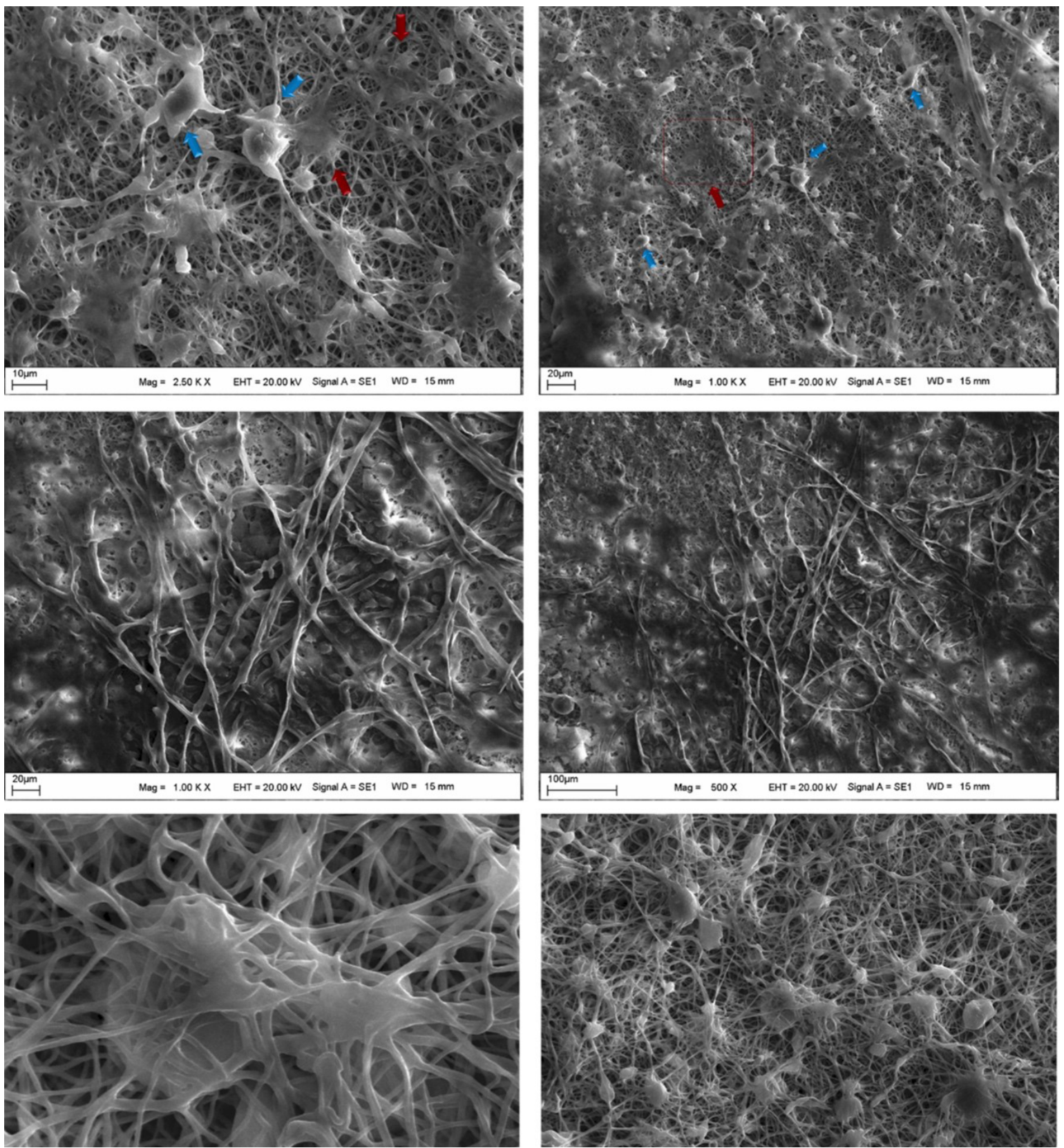

Figure 5. . SEM images of adherent cells on hybrid PU/PCL fibrous mats at different magnifications. Red arrows represent the adherent cells whereas the blue arrows represent the fiber beads. Reprinted with permission from [89] @ 2020 John Wiley and Sons.

of stevia glycoside, then the resultant was mixed with PCL for easy production of nanofibers. The steviol glycosides serves as a crosslinker that provides mechanical strength. The detailed investigations including their morphological nature, water content and oxygen permeability and swelling degree showcased favorable outcome for their use as wound dressing material. Further to support, the cell adhesion and biocompatibility studies have revealed their non-toxic nature and their beneficial characteristics in the cell adhesion and proliferation. The L-929 cells found to grow with good confluency over the hybrid PU/PCL fibrous mats (see Figure 5). The outcome of the study showcased that the developed PU/PCL fibrous mats could be an effective wound dressing materials [89]. In another effort, zinc oxide $(\mathrm{ZnO})$ nanoparticles have been incorporated in poly(3-hydroxybutyrate-co-3-hydroxyvalerate) (PHBV)/ polyethylene oxide (PEO) composite fibers using elect- 
rospinning [90]. The resultant composite fibers have been investigated for their morphological feature and effective incorporation of $\mathrm{ZnO}$ nanoparticles using scanning electron microscopy and Fourier transform infrared (FT-IR) spectroscopy. Further, the composite fibers exhibited good antibacterial efficiency against Staphylococcus aureus (NCIM 2654) and Pseudomonas aeruginosa (NCIM 5032) those are considered as potential pathogens in the wound infection. In addition, the fibers indicated good hemocompatible and biocompatible nature that revealed their potential in antibacterial and antibiofilm material for wound dressing applications [90].

Similarly, curcumin (Cur) loaded zein-silk fibroin-chitosan (ZSFC) nanofibers have been prepared for the improved bioavailability of Cur in the wound healing process [91]. The incorporation of Cur found to improve the mechanical strength and the release study showed an initial burst release followed by steady release profile. In addition, the ZSFC/Cur nanofibers have shown enhanced cell adhesion and proliferation of human gingival fibroblast (HGF-1) cells without any toxicity which indicates their potential application in wound dressing [91]. A similar effort has been also made in the fabrication of Cellulose Acetate/Gelatin (CA/Gel) electros- pun mat incorporated with berberine (Beri) for specific dressing of diabetic foot ulcer [92]. Following the detailed characterization, wound healing performances of the dressing has been evaluated in streptozotocin-induced diabetic rats. The study outcome demonstrated that collagen density and angiogenesis score obtained from the treated animals exhibited a proper wound healing. The observed findings implied that the incorporation of berberine in the electrospun mats did not affect their physico-chemical nature and improved their biological activity in the wound healing [92]. An equal effort has been put forward in the encapsulation of honey and Nepeta dschuparensis plant in polyvinyl alcohol and chitosan electrospun nanofibers for enhanced wound healing [93]. The in vivo studies performed in the rat models have shown a faster wound healing within three weeks for the nanofibers incorporated with honey and plant which implied their potential in effective and faster healing of acute and chronic wounds [93]. Bazmandeh and co-workers adopted dual spinneret approach for the fabrication of electrospun nanofibers mimicking fibrous/gel structure of ECM using chitosan-gelatin/ chitosan-hyaluronic acid [94]. The studies revealed an enhanced cell proliferation rate and excellent wound healing performances in rats confirming their potential for wound healing application [94].

In the continuation of the development of composite
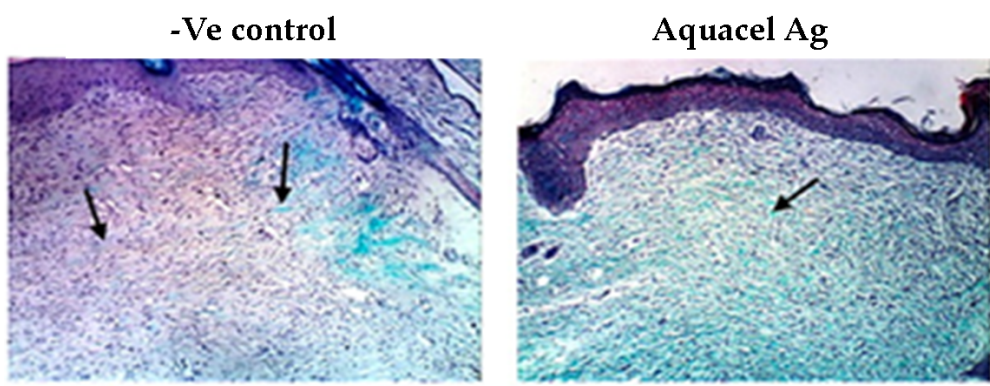

HPCS-AE

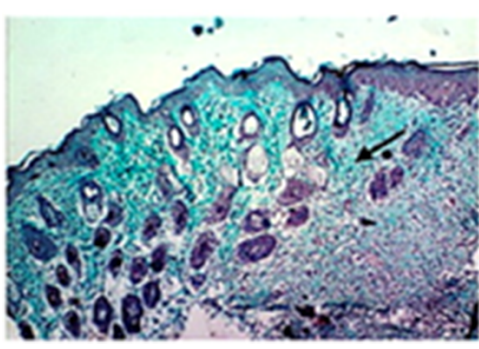

HPCS-CE

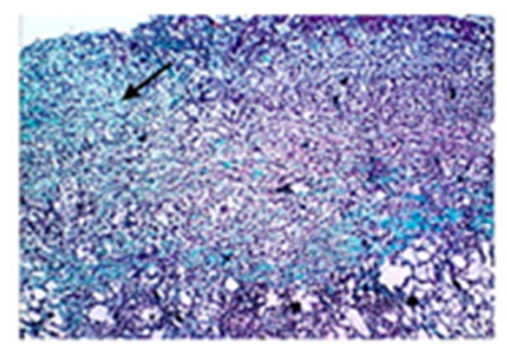

HPCS

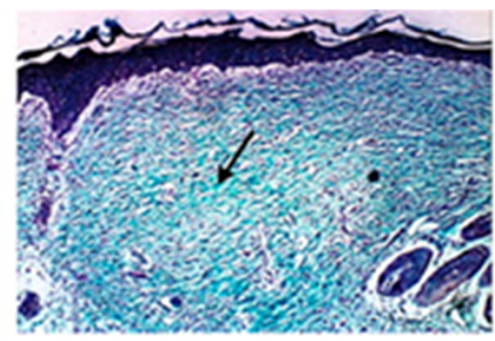

HPCS-AE/CE

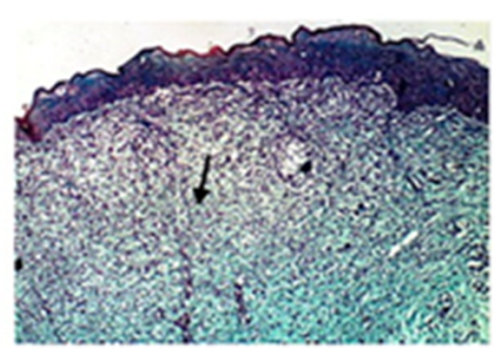

Figure 6. Histopathological evaluation of skin sections. Micrographs of Masson's trichome stained tissues of wounds treated with the developed nanofibrous dressings and the AquacelAg as well as untreated negative control at day 10 (original magnification 100). Notice the dense collagen deposition in the AquacelAg, HPCS, HPCS-AE/CE, HPCS-AE, and HPCS-CE nanofibrous dressings as compared to the negative control (-ve control). Reprinted with permission from [95] (C) 2016 American Chemical Society. 
nanofibers for wound healing purpose, Cleome droserifolia (CE) and Allium sativum (AE) aqueous extracts has been incorporated separately and their combinations in the honey, poly(vinyl alcohol) and chitosan composite nanofibers (HPCS) using electrospinning [95]. The antibacterial studies performed against Staphylococcus aureus, Escherichia coli, Methicillin-resistant S. aureus (MRSA), and multidrug-resistant Pseudomonas aeruginosa indicated good inhibition activities Staphylococcus aureus especially the composite nanofibers incorporated in the combination of both extracts (HPCS-AE/ CE) compared to AquacelAg. Furthermore, the wound healing studies performed in the mice resulted in an enhanced wound closure rate for the HPCS-AE treated animals. The histological evaluations performed using
Hematoxylin and Eosin (H\&E) and Masson's trichrome (MT) staining on different time periods revealed reduction of inflammatory cells compared to control and macrophage cells was greater than the neutrophils in all of the treated wounds. Especially, the MT staining performed on the day 10 confirmed the densest collagen deposition in the wounds treated compared to the control in all the treatments as can be seen from the Figure 6 . The observed results of the study demonstrated the potency of developed nanofibers as competitive candidates for their use in effective wound dressings [95]. Likewise, accountable progresses intensely being made in this aspect, especially in the very recent time several studies reported the use of bovine serum albumin/polyacrylonitrile biohybrid nanofibers [96],

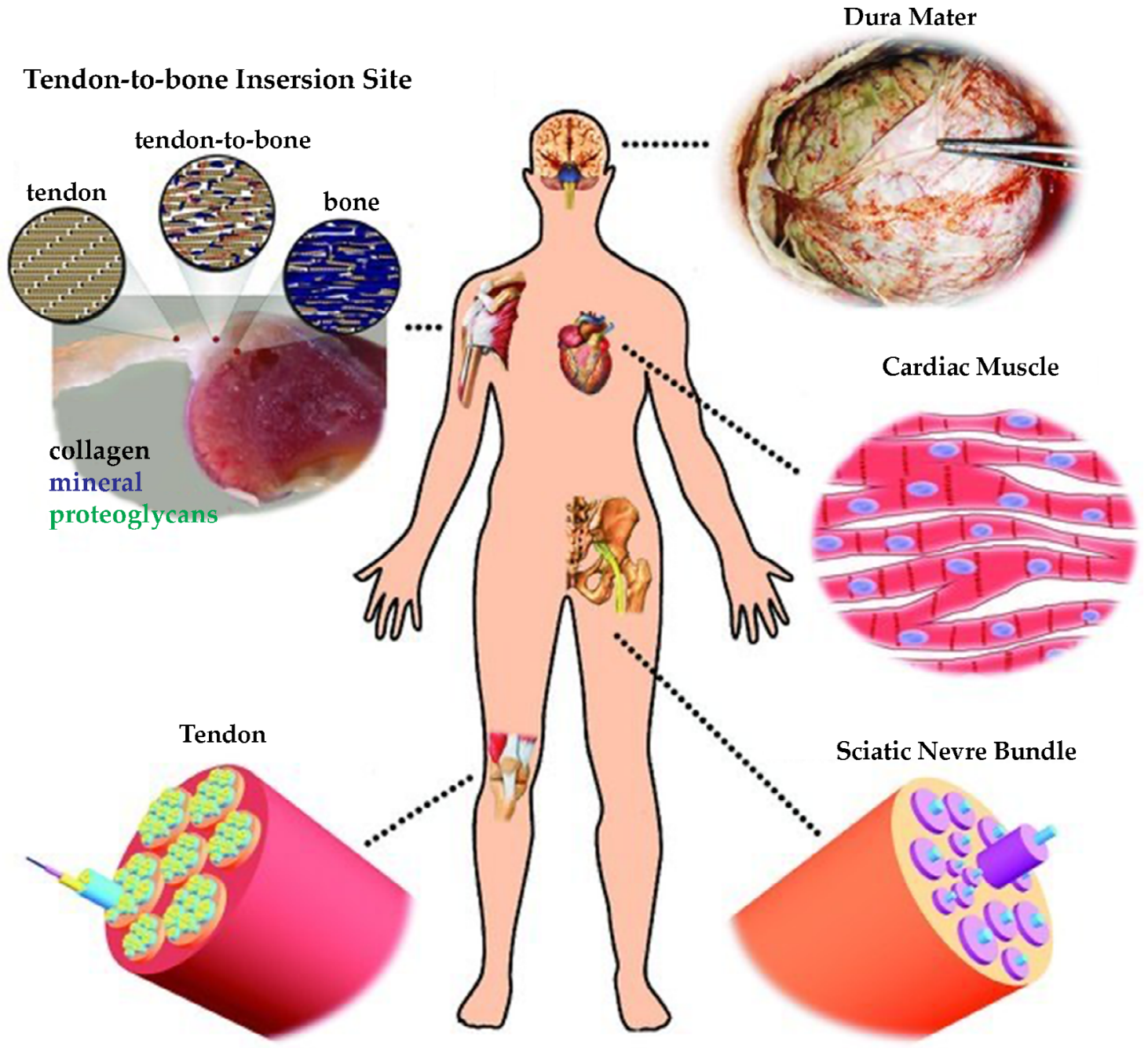

Figure 7. Illustration of some typical examples of tissues in the human body whose regeneration would benefit from the use of nanofiber-based scaffolds with anisotropic structures that could be readily fabricated by electrospinning. Reprinted with permission from [101] (C) 2012 Wiley-VCH Verlag GmbH \& Co. 
poly(ethylene oxide)/gelatin-poly(vinyl alcohol)/chitosan nanofibers [97], PCL/gelatin nanofibers [98], PVA/ hyaluronic acid/L-arginine nanofibers [99] and cellulose acetate/poly(lactic acid) nanofibrous mats [100] for effective wound dressing applications. Therefore, the electrospinning approach has been undoubtedly advanced the wound dressing application for effective wound care management.

\section{Electrospun Nanofibers in Tissue Engineering Application}

Tissue engineering generally adopts the concepts of biology and engineering for reconstruction of various tissues including skin, muscle, bone, nerve and cartilage by using scaffold that offers an interacting environment to promote cell attachment, differentiation, migration and proliferation which leads to form tissues. The morphological nature and alignment of the electrospun nanofibers mimics the natural ECM which provides an excellent structural support for the cells to form new tissues. Especially, alignment of the nanofiber plays critical role in the contact guidance of the cell migration and differentiation. The precise control over biomimetic nature of the electrospun nanofibers is considered to be an important factor for the advancement of tissue engineering in addition to the choice of material. Acknowledging the beneficial features, the electrospun nanofibers offers great possibility in the regeneration of various tissues in the human body as depicted in the Figure 7 [101]. Therefore, to date enormous progress have shown that the electrospun based scaffolds are greatly enhanced the repair/regeneration of different of tissues (e.g., bone, skin, nerve, heart, vascular and muscoskeletal system) due to its inherent properties of large surface area, porosity, stacking/pattering nature, alignment, mechanical strength, complex interface topology and easy functionalization nature $[31,47,102$ 108]. Therefore, we evidently discuss potential of electrospun nanofibers in the engineering of various tissues in the following sections.

\section{Bone Tissue Engineering}

Bone tissue engineering has recently received significant attention to repair the bone defects that are generally caused by several factors including trauma, genetic abnormalities, arthritis, bone infection, defect in remodeling, congenital defects, neoplasm, osteoporosis and deficiencies of calcium and vitamin. The bone is considered as a complex tissue comprised of hierarchical structure which offer protection for internal organs, support body and facilitates movement, therefore repairing their defects holds paramount importance in the clinical significance. Generally, transplantation is opted to treat the bone defects by using autografts and allografts, however several associated drawbacks exit with regard to donors, availability of autologous bones in the body and immune rejection [109-111]. Therefore, in recent years bone tissue engineering have advanced the treatment using several biocompatible materials that has structural and functional interface to remodel the bone defects. As the electrospun nanofibers several beneficial features for the biomedical application, enormous progress has also lead in the fabrication of nanofibers from various natural and synthetic biocompatible polymers incorporated with numerous active agents through several approaches for the purpose of bone tissue engineering.

In this context, a very recent study reported by Samadian and co-workers prepared a bioactive and functional 3D scaffold using gelatin nanofibers and used them in the regeneration of bone defects [112]. Briefly, first the gelatin nanofibers have been prepared by electrospinning and then dispersed in the polylactic acid (PLA)/ polycaprolactone (PCL) polymer solution with different Taurine (Tau) concentration, later converted into 3D scaffold through thermally-induced phase separation technique. The resultant scaffold has been subjected to various characterization studies and the results revealed that the scaffolds possessed excellent porosity, Tau incorporation increased the weight loss rate and wettability nature. The in vitro studies of the scaffold demonstrated excellent cytocompatible and cell viability nature. Further in vivo studies conducted in the Wistar rats exhibited bone defects treated with the scaffold filled with new bone. Especially, the scaffold incorporated with 10\% Tau (PLA/PCL/Gel/Tau 10\%) has shown highest new bone formation, woven bone and angiogenesis as confirmed by computed tomography (CT) image (see Figure 8). Therefore, the developed scaffold can be used for the regeneration of bone defects and potentially employed in the bone tissue engineering application [112]. Another study reported the fabrication of 3D nanofibrous scaffolds of nano-hydroxyapatite/ PLLA/gelatin ( $\mathrm{NHA} / \mathrm{PLA} / \mathrm{GEL}$ ) by combining electrospinning, homogenizing, freeze-drying, and thermal crosslinking techniques that has been further immobilized with bone morphogenetic protein-2 (BMP-2)-derived peptides [113]. The in vitro studies performed on the bone mesenchymal stem cells (BMSCs) revealed favo- 

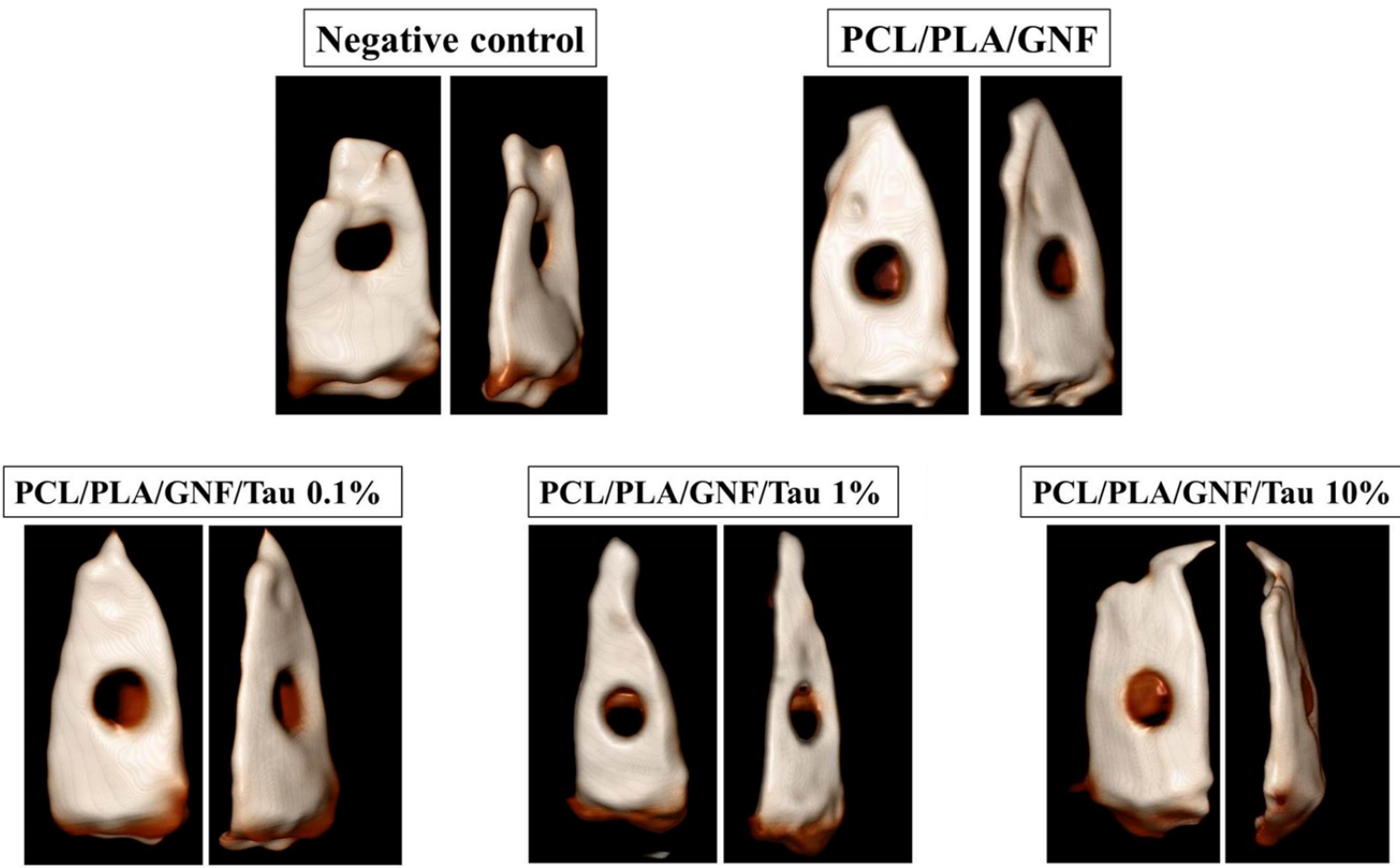

Figure 8. X-ray Computed Tomography (CT) images of damage skull bone. The images were obtained 12 weeks post-implantation. Reprinted from [112] 2020, Springer Nature.

rable biocompatibility and osteoinductivity. Furthermore, the results of the in vivo studies performed using a rat cranial bone defect model confirmed excellent bone regeneration confirming their potential for bone tissue engineering [113]. Wang and co-workers used electrospun polycaprolactone ( $P C L) / g e l a t i n$ nanofibrous scaffold in the dual delivery of alendronate (ALN) and silicate for effective bone remodeling [114]. The developed scaffold demonstrated the bone remodeling of defects in four weeks which has been three times faster than the other groups that might be attributed to the beneficial characteristics of ALN and silicate which inhibited the bone-resorbing process and promoted the boneforming process through guanosine triphosphate-related protein expression prevention and vascularization and bone calcification improvement [114]. In a similar trend, electrospun silk fibroin (SF) nanofibrous scaffold functionalized with two-stage hydroxyapatite (HAp) particles have been employed in the bone regeneration application by using critical-sized calvarial bone defect model [115]. Another study used molybdenum disulfide nanosheets incorporated polycaprolactone/zein com- posite nanofibers in the bone tissue regeneration application [116]. In recent years, significant efforts have been put forward in the fabrication of conductive electrospun scaffold for effective bone tissue engineering. In this context, a representative study demonstrated the fabrication of electrospun carbon nanofibers functionalized with gold nanoparticle and evaluated their performance in the bone tissue engineering application [117]. The outcome confirmed that the developed electrospun conductive nanofibrous scaffold could be successfully employed in the bone tissue engineering application [117].

\section{Nerve Tissue Engineering}

The clinical significance for the treatment of injured peripheral nerves hold great importance and challenge as the injury may leads several complications including sensory, motor or autonomic problems. The severely injured nerves lead to formation of lesions and generated pressure along the nerves that interferes the nerve regeneration. Therefore, tremendous efforts have been continuously made over recent decades for the 


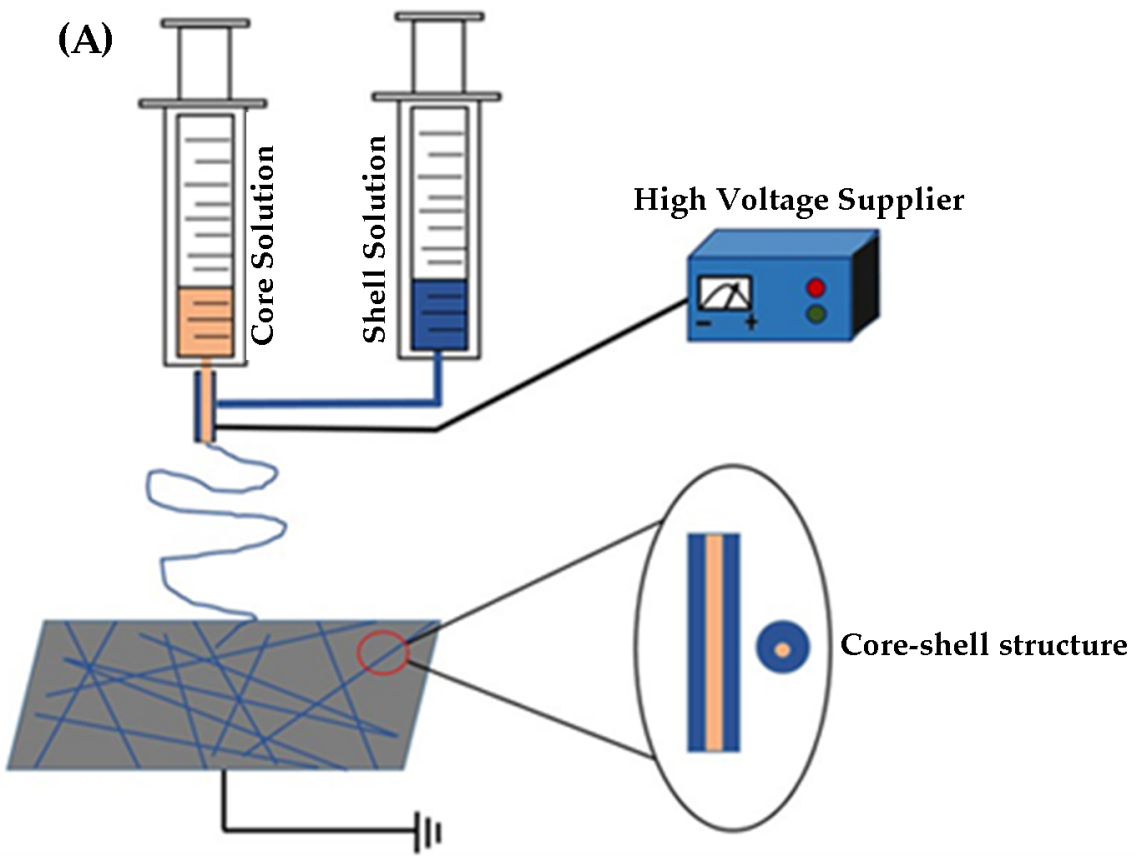

(B)

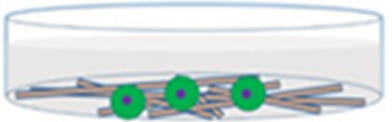

ChangetoDifferantiation Medium
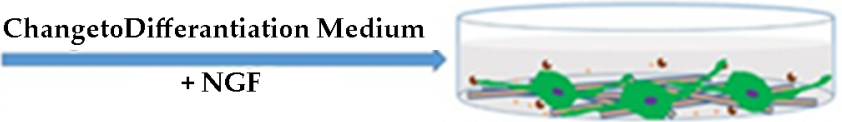

PC12 cells differentiation and neurite extension

(C)
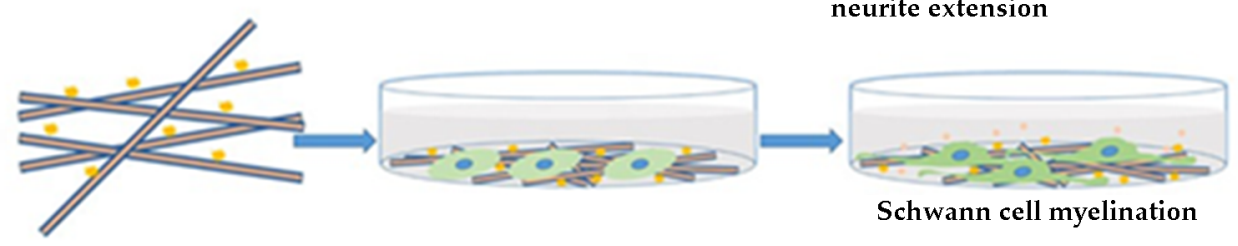

Schwann cell myelination

(D)

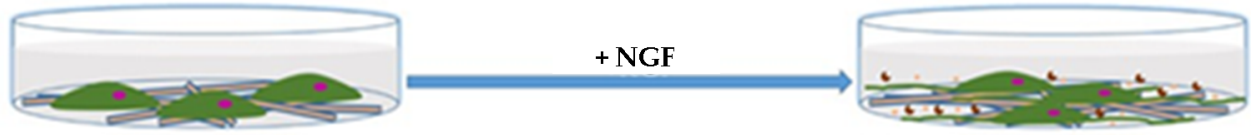

DRG neurons neurite outgrowth
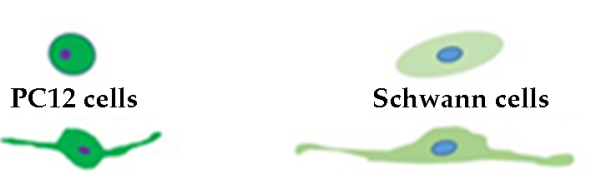

Differentiated PC12 cells

Myelinating Schwann cells

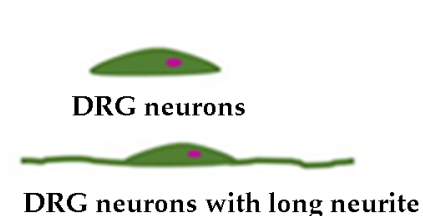

- Released LBP

¿ NGF

- Poly-L-lysine

DRG neurons with long neurite

Figure 9. Schematic illustration of the preparation process and working hypothesis for coaxial electrospun fiber scaffolds. (A) The setup of coaxial electrospinning: the spinneret is composed of two concentric needles; the outer needle is used to deliver the shell solution (blue), while the inner needle is used to eject the core solution (Pink). (B) The LBP encapsulated in the core of coaxial fibers could be released in a sustained manner to promote differentiation of PC12 cells with Differentiation Medium+NGF. (C) Scaffolds coated with Poly-L-lysine could promote the adhesion of Schwann cells, and the released LBP could enhance the myelination of Schwann cells. (D) The neurite outgrowth of DRG neurons might be improved under the synergistic effect of LBP and NGF. Reprinted from [125] 2018 Springer Nature. 
treatment of nerve injuries including autograft/allograft transplantation and nerve guidance conduit (NGC) repair by adopting several approaches and materials [118-123]. The design of scaffold intended for purpose of neural regeneration must consider their cellular compatibility, mechanical strength and guidance of the nerves. In this regard, electrospun nanofiber obviously offer the required microenvironment for the nerve regeneration because of their morphological feature, alignment and integration of various active agents that support the enhanced nerve regeneration. A study reported by Xie and co-workers evidently showcased the effect of alignment of the electrospun nanofiber on guidance of neurite growth [124]. Briefly, electrospun poly( $\varepsilon$-caprolactone) (PCL) nanofibrous scaffolds with random and uniaxial alignment, also double layered scaffold has been prepared by placing the aligned nanofibers on top of the random nanofiber mat for comparison purpose. The dorsal root ganglia (DRG) has been seeded on these scaffolds and evaluated the outgrowth of neurites. Especially, bottom layer of the random nanofibers in the double layer scaffold exhibited a negative impact on the extension of neurites projecting from the DRG compared to single layer of scaffolds with different alignment. This limitation has been overcome by the preseeding Schwann cells. The preseeding of Schwann cells on the double layered scaffolds with uniaxial and random alignment exhibited improved performance. Therefore, the double layered NGC hold great potential in facilitating motor axon regeneration and functional motor recovery of nerves [124].

Functionalization of nanofibrous scaffolds always have significant prominence in the enhanced regeneration. In this context, a neuroprotective and promising in nerve recovery compound lycium barbarum polysaccharide (LBP) has been functionalized in poly (lactic-co-glycolic acid) (PLGA) nanofibrous scaffold through coaxial electrospinning [125]. The process of scaffold preparation and working hypothesis is schematically depicted in Figure 9. The prepared scaffold has been subjected to the morphological characterization, mechanical and water contact angle studies. Further, the release profile of the LBP has been evaluated and the results confirmed that the LBP has been released in fast burst release and constant release. Further, cell proliferation has been studied using PC12 cells and Schwann cells that have shown favorable outcome. Further the differentiation studies performed in the presence of nerve growth factor (NGF) has shown improved performance. Lastly, to explore the potential of scaffold in peripheral nerve repair, the DRG neurons and Schwann cells by observing neurite outgrowth and myelination, respectively. Overall, the LBP loaded scaffold has showcased excellent neural regeneration and could be used as an ideal substrate for the target peripheral nerve injury repair [125]. The conductive nature of scaffolds is important to enhance electrical signal transfer between neural cells. Therefore, several efforts have been devoted in the fabrication of electrospun nanofibers scaffold using conductive polymers or functional materials with conductive properties. As an example, gold nanoparticles (AuNPs) doped polycaprolactone (PCL)/chitosan electrospun nanofibers have been prepared and evaluated their performance in the promotion of peripheral nerve regeneration [126]. The biological response studies conducted using Schwann cells revealed improved cell attachment and higher proliferation following five days of incubation [126]. In another study, conductive polymers poly $N$-vinylpyrrole and poly(3-hexylthiophene) have been used with cellulose for the fabrication of conductive electrospun nanofibrous scaffold and demonstrated positive outcome [127]. In similar trend, many efforts have been devoted using carbon nanotubes [128], poly\{[aniline tetramer methacrylamide]-co[dopamine methacrylamide]-co-[poly(ethylene glycol) methyl ether methacrylate]\} [129], and graphene [130].

\section{Cartilage Tissue Engineering}

Cartilage is a connective tissue of diarthrodial joint which is primarily composed chondrocytes and dense ECM without blood vessels and nerve distributions. There are several factors that cause cartilage damage including trauma, aging and sports related activities which leads osteoarthritis and debilitating pain. The damaged cartilage holds poor regenerative capacity, therefore regeneration of the cartilage has attracted huge attention [131-133]. To date, cemented progress has been also made on the cartilage tissue engineering by using the electrospun nanofibrous scaffolds acknowledging their beneficial nature in various aspects. For instance, Chen and co-workers fabricated hyaluronic acid (HA) modified electrospun gelatin/PLA nanofibrous 3D scaffold (3DS-2) and evaluated their potency in the cartilage regeneration [134]. A scaffold (3DS-1) without the HA has been fabricated for the comparison purpose. Figure 10A schematically illustrates procedure for fabrication of scaffolds which involved three steps including electrospinning, freeze-drying and cross-linking. The obtained scaffolds have been subjected to various 
(A)
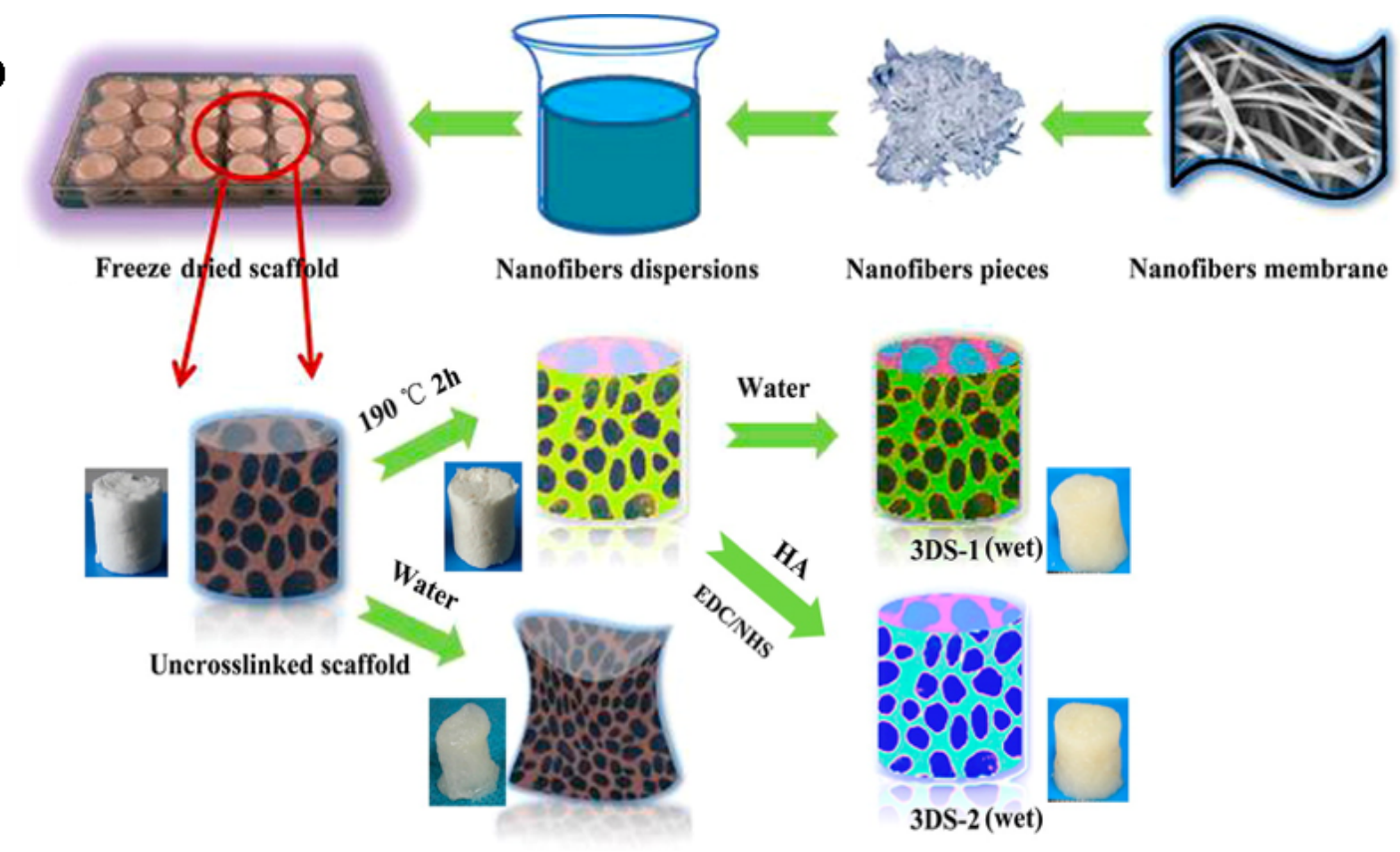

(B)
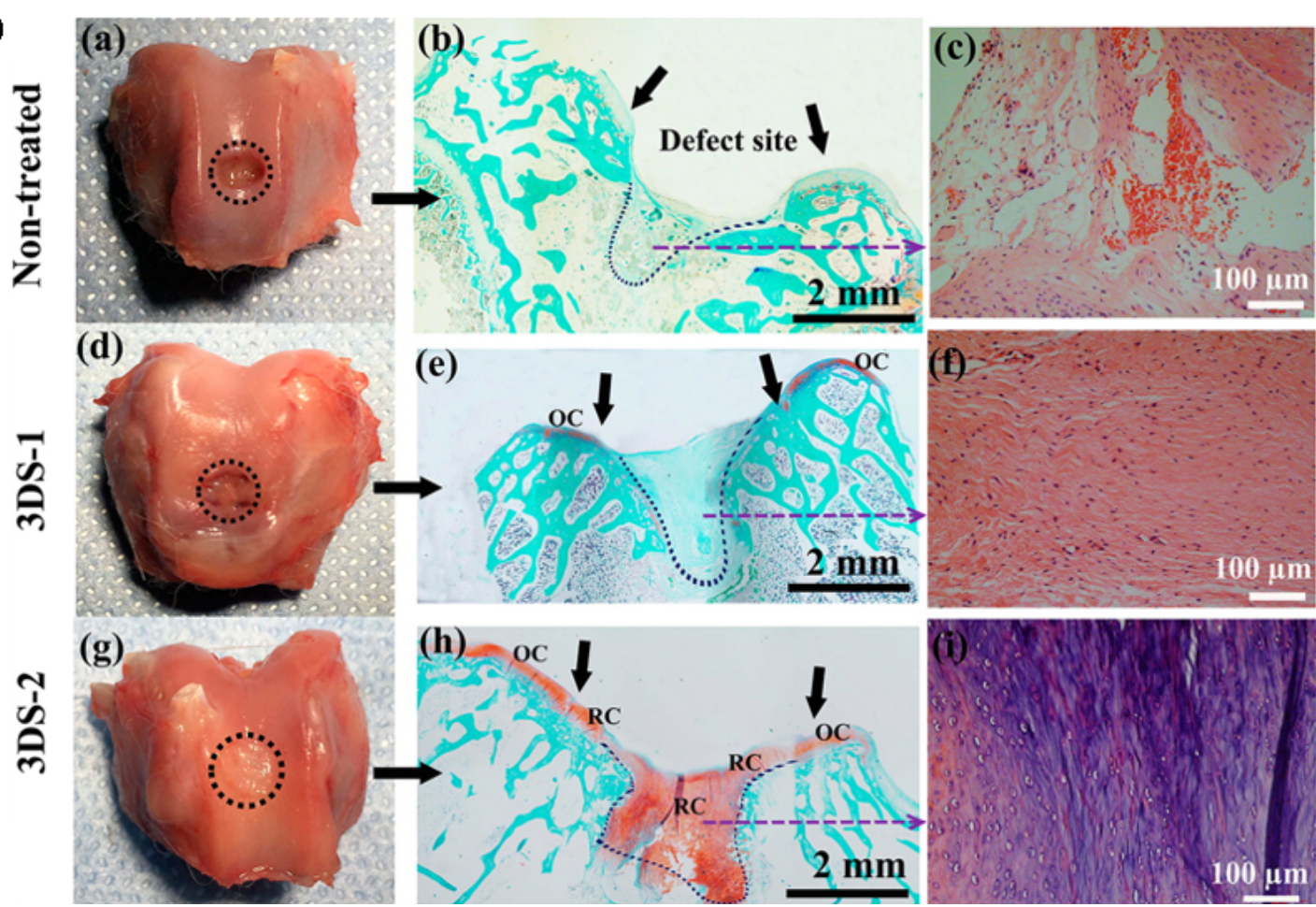

Figure 10. (A) Schematic illustration for 3D scaffold preparation. (B) Macroscopic images (a, $d$, and g) of the cartilage joints from three groups at 12 weeks after surgery. Histological analysis of cartilage defect area from three groups at 12 weeks after surgery, stained with Safranin O-fast green (b, e, and h) and H\&E (c, f, and i). Arrows and dotted lines indicated the defect sites. OC: original cartilage tissue. RC: repaired cartilage tissue. Reprinted with permission from [134] @ 2016 American Chemical Society. 
characterization studies to understand their structure, mechanical properties and water absorption. Both the scaffolds have shown elastic nature in the wet state. In vitro cytocompatibility studies have been performed using chondrocytes that demonstrated their biocompatible nature. Furthermore, an in vivo cartilage regeneration study has been conducted using rabbits as articular cartilage injury model and the corresponding results are presented in Figure 10B. Following 12 weeks of implantation, obvious defects exists in the untreated control, whereas the defect became smaller with dense fibrous tissue. Especially, the defect in the animal treated with 3DS-2 exhibited complete cartilaginous regeneration because of the presence of HA. Most importantly, the Safranin O-fast green of the 3DS-2 confirms well integration of regenerated cartilage (red color) with original (see Figure 10Bh) which have great potential for cartilage tissue engineering [134].

Another study used chitosan/poly (vinyl alcohol) electrospun nanofibrous scaffolds to mimic ECM for the differentiation of human adipose tissue derived mesenchymal stem cells (ADSCs) to chondrogenic cells [135]. The study outcome suggested that the developed scaffold system exhibited excellent proliferation and differentiation of the cells which indicates their performance in cartilage tissue engineering [135]. A recent study reported by Liu and co-workers have demonstrated the fabrication of poly( $\varepsilon$-caprolactone) (PCL) framework reinforced with poly(lactic-co-glycolic acid) (PLGA) electrospun nanofiber incorporated hydroxybutyl chitosan (HBC) hydrogels [136]. Briefly, PLGA nanofibers have been prepared through electrospinning and frag mented through an aminolysis degradation reaction. Then, the obtained nanofibers have been mixed with HBC hydrogels (HBC-NF hydrogels). Following detailed characterization and initial cell proliferation studies, 3D printing aooroach has been employed in the preparation of PCL framework with internal microchannels and then HBC-NF hydrogels have been injected. Figure 11 clearly indicates the preparation process and differentiation of the human mesenchymal stem cells (hMSCs) in vitro and cartilage regeneration in vivo. Especially, the in vivo study demonstrated significant induction of cartilage differentiation of the hMSCs [136]. Therefore, it is well evidenced that efforts have been continuously made on the fabrication of scaffolds by adopting different strategies and materials with various architecture in order to achieve enhanced cartilage regeneration.

\section{Other tissue engineering and commercial prospectus}

Apart from the above tissue engineering applications, the electrospun nanofibers have been extensively explored for their potentials in other engineering other tissues including cardiac [137], skeletal muscle [138], tendon/ligament [139], blood vessel [107], dental [140], vascular [141], urethral [142] and cornea [143]. Based on the extensive discussion made throughout the article, it has been well evidenced that the electrospun nanofibers have been vastly used in the fabrication of scaffolds by adopting several approaches. The electrospinning technology is not just a laboratory research oriented, as it offers huge possibilities in upscaling of the products successfully established, to date significant electrospun nanofiber products has been commercialized for applications ranging from environment to biomedicine [144]. To highlight specifically, Polyremedy offers a range of HealSmart product for the wound care management [145]. Similarly, Nicast provides nanofibrous AVfloTM vascular graft medical device for hemodialysis that initiates the dialysis within $24 \mathrm{~h}$ [146]. Furthermore, BioSurfaces Inc. offers drug loaded electrospun materials including Bio-Spun ${ }^{\mathrm{TM}}$ Bioactive Bandage, Bio-Spun ${ }^{\mathrm{TM}}$ Antimicrobial Suture and Bio-Spun ${ }^{\mathrm{TM}}$ Artificial Artery for different biomedical applications [147].

\section{CONCLUSION and FUTURE OUTLOOK}

To conclude, the review provides an overview on beneficial features of the electrospun nanofibers that extend their potentiality in different biomedical applications. Especially, as discussed throughout the article, the electrospun nanofibers have been extensively employed in the wound dressing and tissue engineering applications. Indeed, the electrospun nanofibers have made huge impact on the wound dressing and tissue engineering application that obviously advanced the field by commercializing the materials, however several associated challenges need to be addressed. Although concrete efforts have been made over couple of decades using various synthetic polymers, natural polymers and their blends, still most of the research initiatives are not transferred to industrial scale and commercialized that can be understood from the list of products available in the market to date. Therefore, the future efforts have to be executed in different ways to address variety of existing challenges. Especially, the initial planning of the designing scaffolds should consider the human equivalent doses and their compatibility since it is a critical factor that limits the transforming the technology 
a

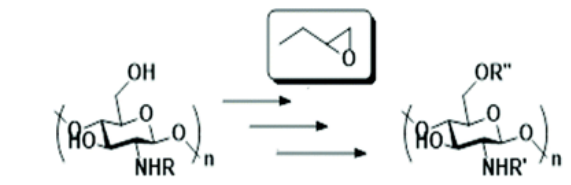

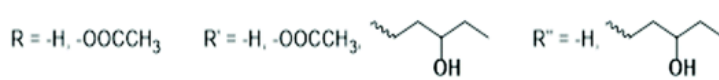
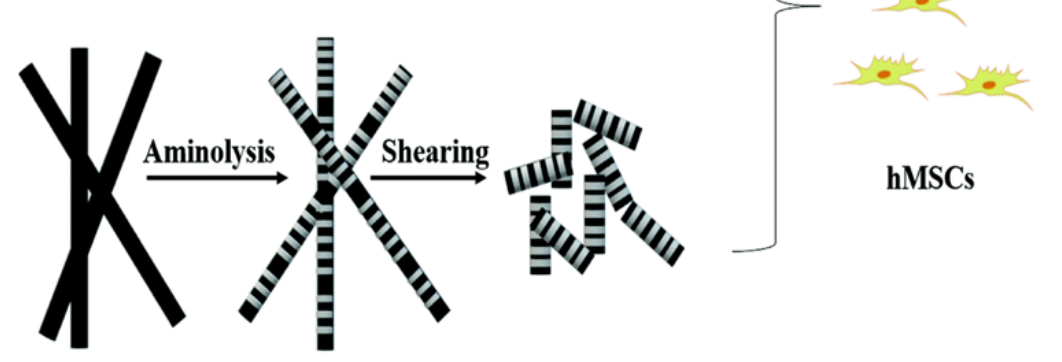

hMSCs

\section{PLGA nanofibers}

b
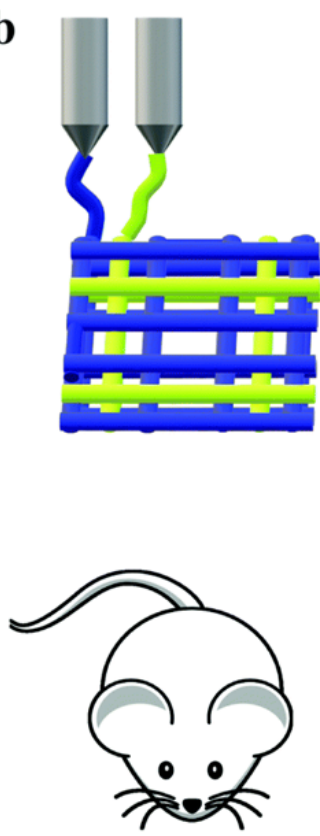

$\longrightarrow \mathrm{PCL}$

\section{Hydrogel perfusion}

\section{Short nanofibers}

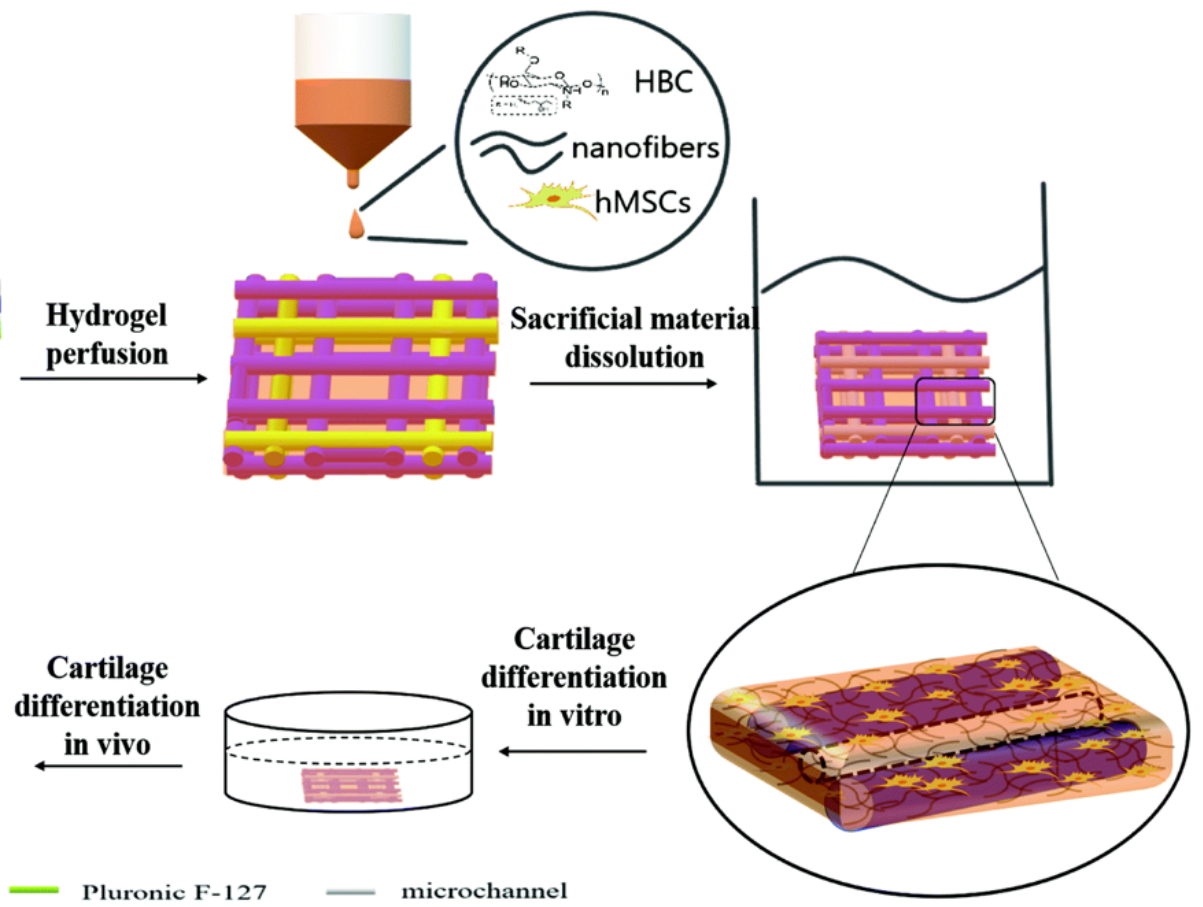

Figure 11. (a) Schematic illustration of the fabrication of the HBC-NF hydrogels laden with hMSCs. The hMSCs were encapsulated in the HBC-NF hydrogels for growth and cartilage differentiation in vitro. (b) Schematic representation of the 3D fabrication of the PCL-reinforced HBC-NF hydrogel scaffold with internal microchannels for cartilage differentiation in vivo. The 3D framework was coprinted with PCL and Pluronic F-127 (sacrificial material). After the injection of the cell-laden HBC-NF hydrogels, the sacrificial material was washed out, thus leading to the formation of internal microchannels. The cell-laden composite scaffold was then transplanted into nude mice for cartilage differentiation in vivo. Reprinted with permission from [136] @ 2020 The Royal Society of Chemistry. 
to clinical phase. Furthermore, industrial viability of the developed technology should be foreseen for their successful commercialization. Ultimately, the future directions in the design and development of nanofibrous scaffolds must consider the improving the quality of treatments for the patients.

Acknowledgments - Prof. Uyar acknowledges the startup funding from the College of Human Ecology at Cornell University.

\section{References}

1. T. Lin, J. Fang, Fundamentals of electrospinning \& electrospun nanofibers, DEStech Publications, Inc, Pennsylvania, USA 2017.

2. Z. Li, C. Wang, One-dimensional nanostructures: Electrospinning technique and unique nanofibers, SpringerVerlag, Berlin Heidelberg, Germany, 2013.

3. B. Ding, X. Wang, J. Yu, Electrospinning: Nanofabrication and applications, William Andrew, Elsevier, Amsterdam, Netherland, 2019.

4. G.R. Mitchell, Electrospinning: Principles, practice and possibilities, The Royal Society of Chemistry, Cambridge, UK, 2015.

5. J.H. Wendorff, S. Agarwal, A. Greiner, Electrospinning: Materials, processing, and applications, Wiley, Weinheim, Germany, 2012.

6. J. Xue, T. Wu, Y. Dai, Y. Xia, Electrospinning and electrospun nanofibers: Methods, materials, and applications, Chem. Rev., 119 (2019) 5298-5415.

7. S. Mohammadzadehmoghadam, Y. Dong, S. Barbhuiya, L. Guo, D. Liu, R. Umer, X. Qi, Y, Tang, Electrospinning: Current status and future trends, In: S. Fakirov (eds), Nano-size polymers, Springer, Cham, Switzerland, 2016, pp. 89-154.

8. F. Topuz, T. Uyar, Electrospinning of cyclodextrin functional nanofibers for drug delivery applications, Pharmaceutics, 11 (2019) 6.

9. A.F. Ismail, N. Hilal, J. Jaafar, C. Wright, Nanofiber membranes for medical, environmental, and energy applications, CRC Press, Boca Raton, FL, USA 2019.

10. B. Ding, J. Yu, Electrospun nanofibers for energy and environmental applications, Springer, Berlin/Heidelberg, Germany, 2014.

11. G. Sun, L. Sun, H. Xie, J. Liu, Electrospinning of nanofibers for energy applications, Nanomaterials, 6 (2016) 129.

12. H. Liu, C.R. Gough, Q. Deng, Z. Gu, F. Wang, X. Hu, Recent advances in electrospun sustainable composites for biomedical, environmental, energy, and packaging applications, Int. J. Mol. Sci., 21 (2020) 4019.

13. Z. Tong, L. Huang, W. Lei, H. Zhang, S. Zhang, Carboncontaining electrospun nanofibers for lithium-sulfur battery: Current status and future directions, J. Energy Chem., 54 (2021) 254-273.

14. M. Focarete, C. Gualandi, S. Ramakrishna, Filtering media by electrospinning, Springer, Cham, Switzerland, 2018.
15. B. Balusamy, A. Senthamizhan, T. Uyar, Functionalized electrospun nanofibers as a versatile platform for colorimetric detection of heavy metal ions in water: A review, Materials, 13 (2020) 2421

16. A. Senthamizhan, A. Çelebioğlu, B. Balusamy, T. Uyar, Immobilization of gold nanoclusters inside porous electrospun fibers for selective detection of $\mathrm{Cu}(\mathrm{II})$ : $\mathrm{A}$ strategic approach to shielding pristine performance, Sci. Rep., 5 (2015) 15608.

17. A. Senthamizhan, B. Balusamy, Z. Aytaç, T. Uyar, Grain boundary engineering in electrospun $\mathrm{ZnO}$ nanostructures as promising photocatalysts, CrystEngComm., 18 (2016) 6341-6351.

18. B. Balusamy, A. Senthamizhan, T. Uyar, Surface functionalized electrospun nanofibers for removal of toxic pollutants in water, In: A.F. Ismail, N. Hilal, J. Jaafar, C. Wright (Eds.), Nanofiber Membranes for Medical, Environmental, and Energy Applications, CRC Press, Boca Raton, FL, USA, 2019, pp. 189-213.

19. A. Senthamizhan, B. Balusamy, T. Uyar, Electrospun filters for organic pollutants removal, In: M. Focarete, C. Gualandi, S. Ramakrishna, (Eds.), Filtering Media by Electrospinning, Springer, Cham, Switzerland, 2018, pp. 115-150.

20. A. Senthamizhan, A. Celebioglu, T. Uyar, T, Real-time selective visual monitoring of $\mathrm{Hg}^{2+}$ detection at ppt level: An approach to lighting electrospun nanofibers using gold nanoclusters, Sci. Rep., 5 (2015) 10403.

21. A. Senthamizhan, B. Balusamy, A. Çelebioğlu, T. Uyar, "Nanotraps" in porous electrospun fibers for effective removal of lead(II) in water, J. Mater. Chem. A, 4 (2016) 2484-2493.

22. B. Balusamy, O.F. Sarioğlu, A. Senthamizhan, T. Uyar, Rational design and development of electrospun nanofibrous biohybrid composites, ACS Appl. Bio Mater., 2 (2019) 31283143.

23. A. Senthamizhan, T. Uyar, Electrospun fluorescent nanofibers for explosive detection, in: A. Macagnano, E. Zampetti, E. Kny (Eds.), Electrospinning for High Performance Sensors, Springer, Cham, Switzerland, 2015, pp. 179-204.

24. S. Anitha, B. Brabu, K.P. Rajesh, T.S. Natarajan, Fabrication of UV sensor based on electrospun composite fibers, Mater. Lett., 92 (2013) 417-420.

25. X. Wang, J. Yu, G. Sun, B. Ding, Electrospun nanofibrous materials: a versatile medium for effective oil/water separation, Mater. Today, 19 (2016) 403-414

26. A. Senthamizhan, A. Çelebioğlu, T. Uyar, Flexible and highly stable electrospun nanofibrous membrane incorporating gold nanoclusters as an efficient probe for visual colorimetric detection of Hg(II), J. Mater. Chem. A, 2 (2014) 12717-12723.

27. B. Balusamy, A. Senthamizhan, T. Uyar, Functionalized electrospun nanofibers as colorimetric sensory probe for mercury detection: A review, Sensors, 19 (2019) 4763.

28. D. Lv, M. Zhu, Z. Jiang, S. Jiang, Q. Zhang, R. Xiong, C. Huang, Green electrospun nanofibers and their application in air filtration, Macromol. Mater. Eng., 303 (2018) 1800336.

29. B. Balusamy, A. Çelebioğlu, A. Senthamizhan, T. Uyar, Progress in the design and development of "fast-dissolving" electrospun nanofibers based drug delivery systems - A systematic review, J. Controlled Release, 326 (2020) 482509.

30. A.B. Tekinay, B. Balusamy, A. Senthamizhan, T. Uyar, Neuroregenerative Nanotherapeutics, In: A.B. Tekinay (Ed.), Nanomaterials for Regenerative Medicine. Stem Cell Biology and Regenerative Medicine, Springer, Humana, Cham, Switzerland, 2019, pp. 143-181. 
31. T. Uyar, E. Kny, Electrospun Materials for Tissue Engineering and Biomedical Applications: Research, Design and Commercialization, first ed., Woodhead Publishing Series in Biomaterials, Elsevier, Cambridge, 2017.

32. A. Senthamizhan, B. Balusamy, T. Uyar, Recent progress on designing electrospun nanofibers for colorimetric biosensing applications, Curr. Opin. Biomed. Eng., 13 (2020) 1-8.

33. B. Balusamy, A. Senthamizhan, T. Uyar, Design and development of electrospun nanofibers in regenerative medicine, In: A.B. Tekinay (Ed.), Nanomaterials for Regenerative Medicine. Stem Cell Biology and Regenerative Medicine, Springer, Humana, Cham, Switzerland, 2019, pp. 47-79.

34. A. Senthamizhan, B. Balusamy, T. Uyar, Electrospinning - A versatile processing technology for producing biomedical materials and tissue engineering, In: T. Uyar, E. Kny (Eds.), Electrospun Materials for Tissue Engineering and Biomedical Applications: Research, Design and Commercialization, Woodhead Publishing Series in Biomaterials, Elsevier, Cambridge, UK, 2017, pp. 3-41.

35. S. Anitha, B. Brabu, D.J. Thiruvadigal, C. Gopalakrishnan, T.S. Natarajan, Optical, bactericidal and water repellent properties of electrospun nano-composite membranes of cellulose acetate and ZnO, Carbohydr. Polym., 87 (2012) 1065-1072

36. B. Balusamy, A. Senthamizhan, T. Uyar, In vivo safety evaluations of electrospun nanofibers for biomedical applications, in: T. Uyar, E. Kny (Eds.), Electrospun Materials for Tissue Engineering and Biomedical Applications: Research, Design and Commercialization, Woodhead Publishing Series in Biomaterials, Elsevier, Cambridge, UK, 2017, pp. 101-113.

37. A.B. Tekinay, Nanomaterials for Regenerative Medicine. Stem Cell Biology and Regenerative Medicine, Springer, Humana, Cham, Switzerland, 2019.

38. A. Senthamizhan, B. Balusamy, T. Uyar, Glucose sensors based on electrospun nanofibers: A review, Anal. Bioanal. Chem., 408 (2016) 1285-1306.

39. S. Chen, J.V. John, A. McCarthy, J. Xie, New forms of electrospun nanofiber materials for biomedical applications, J. Mater. Chem. B, 8 (2020) 3733-3746.

40. S. Anitha, B. Brabu, D.J. Thiruvadigal, C. Gopalakrishnan, T.S. Natarajan, Preparation of free-standing electrospun composite $\mathrm{ZnO}$ membrane for antibacterial applications, Adv. Sci. Lett., 5 (2012) 468-474.

41. A. Senthamizhan, B. Balusamy, Z. Aytac, T. Uyar, Ultrasensitive electrospun fluorescent nanofibrous membrane for rapid visual colorimetric detection of $\mathrm{H}_{2} \mathrm{O}_{2}$, Anal. Bioanal. Chem., 408 (2016) 1347-1355.

42. B. Balusamy, A. Senthamizhan, T. Uyar, Electrospun nanofibrous materials for wound healing applications, In: T. Uyar, E. Kny (Eds.), Electrospun Materials for Tissue Engineering and Biomedical Applications: Research, Design and Commercialization, Woodhead Publishing Series in Biomaterials, Elsevier, Cambridge, UK, 2017, pp. 147-177.

43. S. Sabra, D.M. Ragab, M.M. Agwa, S. Rohani, Recent advances in electrospun nanofibers for some biomedical applications, Eur. J. Pharm. Sci., 144 (2020) 105224

44. S, Homaeigohar, A.R. Boccaccini, Antibacterial biohybrid nanofibers for wound dressings, Acta Biomater., 107 (2020) $25-49$

45. Y. Zhang, X. Liu, L. Zeng, J. Zhang, J. Zuo, J. Zou, J. Ding, X Chen, Polymer fiber scaffolds for bone and cartilage tissue engineering. Adv. Funct. Mater., 29 (2019) 1903279.
46. X. Wang, B. Ding, B. Li, Biomimetic electrospun nanofibrous structures for tissue engineering, Mater. Today, 16 (2013) 229-241.

47. X. Gao, S. Han, R. Zhang, G. Liu, J. Wu, Progress in electrospun composite nanofibers: composition, performance and applications for tissue engineering, J. Mater. Chem. B, 7 (2019) 7075-7089.

48. E.J. Mulholland, Electrospun biomaterials in the treatment and prevention of scars in skin wound healing, Front. Bioeng. Biotechnol., 8 (2020) 481.

49. A. Keirouz, M. Chung, J. Kwon, G. Fortunato, N. Radacsi, 2D and $3 \mathrm{D}$ electrospinning technologies for the fabrication of nanofibrous scaffolds for skin tissue engineering: A review, Wiley Interdiscip. Rev. Nanomed. Nanobiotechnol., 12 (2020) e1626.

50. Y. Zhang, X. Liu, L. Zeng, J. Zhang, J. Zuo, J. Zou, J. Ding, X. Chen, Polymer fiber scaffolds for bone and cartilage tissue engineering, Adv. Func. Mater., 29 (2019) 1903279.

51. M. Xue, C.J. Jackson, Extracellular matrix reorganization during wound healing and its impact on abnormal scarring, Adv. Wound Care, 4 (2015) 119-136.

52. E.R. Ghomi, S. Khalili, S.N. Khorasani, R.E. Neisiany, S. Ramakrishna, Wound dressings: Current advances and future directions, J. Appl. Polym. Sci., 136 (2019) 47738.

53. M. Rodrigues, N. Kosaric, C.A. Bonham, G.C. Gurtner, Wound healing: A cellular perspective, Physiol. Rev., 99 (2019) 665706.

54. G.C. Gurtner, S. Werner, Y. Barrandon, M.T. Longaker, Wound repair and regeneration, Nature, 453 (2008) 314-321.

55. G. Han, R. Ceilley, Chronic wound healing: A review of current management and treatments, Adv. Ther., 34 (2017) 599-610.

56. M.E. Okur, I.D. Karantas, Z. Senyiğit, N.ü. Okur, P.I. Siafaka, Recent trends on wound management: New therapeutic choices based on polymeric carriers, Asian J. Pharm. Sci., 2020, DOI: 10.1016/j.ajps.2019.11.008.

57. S. Schreml, R.M. Szeimies, L. Prantl, S. Karrer, M. Landthaler, P. Babilas, Oxygen in acute and chronic wound healing, British J. Dermatol., 163 (2010) 257-268.

58. P. Martin, R. Nunan, Cellular and molecular mechanisms of repair in acute and chronic wound healing, Brit. J. Dermatol., 173 (2015) 370-378.

59. M. Kokabi, M. Sirousazar, Z.M. Hassan, PVA-clay nanocomposite hydrogels for wound dressing, Eur. Polym. J., 43 (2007) 773-781.

60. S.K. Purna, M. Babu, Collagen based dressings-a review, Burns, 26 (2000) 54-62

61. M. Abrigo, S.L. McArthur, P. Kingshott, Electrospun nanofibers as dressings for chronic wound care: Advances, challenges, and future prospects, Macromol. Biosci., 14 (2014) 772-792.

62. Y. Pilehvar-Soltanahmadi, M. Dadashpour, A. Mohajeri, A. Fattahi, R. Sheervalilou, N. Zarghami, An overview on application of natural substances incorporated with electrospun nanofibrous scaffolds to development of innovative wound dressings, Mini Rev. Med. Chem., 18 (2018) 414-427.

63. K.A. Rieger, N.P. Birch, J.D. Schiffman, Designing electrospun nanofiber mats to promote wound healing - a review, J. Mater. Chem. B, 1 (2013) 4531-4541.

64. R. Augustine, E.A. Dominic, I. Reju, B. Kaimal, N. Kalarikkal, S. Thomas, Electrospun polycaprolactone membranes incorporated with $\mathrm{ZnO}$ nanoparticles as skin substitutes with enhanced fibroblast proliferation and wound healing, RSC Adv., 4 (2014) 24777-24785. 
65. T.T.T. Nguyen, C. Ghosh, S.G. Hwang, L.D. Tran, J.S. Park, Characteristics of curcumin-loaded poly(lactic acid) nanofibers for wound healing, J. Mater. Sci., 48 (2013) 7125 7133.

66. S. García-Salinas, M. Evangelopoulos, E. Gámez-Herrera, M. Arruebo, S. Irusta, F. Taraballi, G. Mendoza, E. Tasciotti, Electrospun anti-inflammatory patch loaded with essential oils for wound healing, Int. J. Pharm., 577 (2020) 119067.

67. H. Bahrami, S.H. Keshel, A.J. Chari, E. Biazar, Human unrestricted somatic stem cells loaded in nanofibrous $\mathrm{PCL}$ scaffold and their healing effect on skin defects, Artif. Cells Nanomed. Biotechnol., 44 (2016) 1556-1660.

68. M. Sabitha, S. Rajiv, Preparation and characterization of ampicillin-incorporated electrospun polyurethane scaffolds for wound healing and infection control, Polym. Eng. Sci., 55 (2015) 541-548.

69. D. Gao, Y. Mi, Z. Gao, Green approaches for the fabrication of electrospun poly (vinyl alcohol) nanofibers loaded epidermal growth factor derivative, Mater. Lett., 276 (2020) 128237.

70. K. Lee, S. Lee, Electrospun nanofibrous membranes with essential oils for wound dressing applications, Fibers Polym. 21 (2020) 999-1012.

71. E. Gámez, H. Elizondo-Castillo, J. Tascon, S. García-Salinas, N. Navascues, G. Mendoza, M. Arruebo, S. Irusta, Antibacterial effect of thymol loaded SBA-15 nanorods incorporated in PCL electrospun fibers, Nanomaterials, 10 (2020) 616.

72. J.O.D. Malafatti, M.P. Bernardo, F.K.V. Moreira, H. Ciol, N.M Inada, L.H.C. Mattoso, E.C. Paris, Electrospun poly(lactic acid) nanofibers loaded with silver sulfadiazine/[Mg-Al] layered double hydroxide as an antimicrobial wound dressing, Polym. Adv. Technol., 31 (2020) 1377-1387.

73. B. Brabu, S. Haribabu, M. Revathy, S. Anitha, M. Thangapandiyan, K.R. Navaneethakrishnan, C. Gopalakrishnan, S.S. Murugan, T.S. Kumaravel, Biocompatibility studies on lanthanum oxide nanoparticles, Toxicol. Res., 4 (2015) 1037-1044.

74. A. Senthamizhan, D. Fragouli, B. Balusamy, B. Patil, M. Palei, S. Sabella, T. Uyar, A. Athanassiou, Hydrochromic carbon dots as smart sensors for water sensing in organic solvents, Nanoscale Adv., 1 (2019) 4258-4267.

75. V. Kalyanaraman, S.V. Naveen, N. Mohana, R.M. Balaje, K.R. Navaneethakrishnan, B. Brabu, S.S. Murugan, T.S. Kumaravel, Biocompatibility studies on cerium oxide nanoparticles combined study for local effects, systemic toxicity and genotoxicity via implantation route, Toxicol. Res., 8 (2019) 25-37.

76. N.A.L. Flower, B. Brabu, M. Revathy, C. Gopalakrishnan, S.V.K. Raja, S.S. Murugan, T.S. Kumaravel, Characterization of synthesized silver nanoparticles and assessment of its genotoxicity potentials using the alkaline comet assay, Mutat. Res., 742 (2012) 61-65.

77. B. Brabu, K. Yamuna Gowri, S. Anitha, C. Gopalakrishnan, S.S Murugan, T.S. Kumaravel, Characterization and bacterial toxicity of lanthanum oxide bulk and nanoparticles, J. Rare Earths, 30 (2012) 1298.

78. B. Balusamy, B.E. Taştan, S.F. Ergen, T. Uyar, T. Tekinay, Toxicity of lanthanum oxide (La2O3) nanoparticles in aquatic environments, Environ. Sci. Processes Impacts, 17 (2015) 1265-1270.

79. Y. Han, Y. Jiang‡, Y. Li, M. Wang, T. Fan, M. Liu, Q. Ke, H. Xu, Z. Yi, An aligned porous electrospun fibrous scaffold with embedded asiatic acid for accelerating diabetic wound healing, J. Mater. Chem. B, 7 (2019) 6125-6138.
80. M.A. Taemeh, A. Shiravandi, M.A. Korayem, H. Daemi, Fabrication challenges and trends in biomedical applications of alginate electrospun nanofibers, Carbohydr. Polym., 228 (2020) 115419.

81. A.D.J. Bombin, N.J. Dunne, H.O. McCarthy, Electrospinning of natural polymers for the production of nanofibres for wound healing applications, Mater. Sci. Eng. C, 114 (2020) 110994.

82. J.A. Matthews, G.E. Wnek, D.G. Simpson, G.L. Bowlin, Electrospinning of collagen nanofibers, Biomacromolecules, 3 (2002) 232-238.

83. T. Zhou, N. Wang, Y. Xue, T. Ding, X. Liu, X. Mo, J. Sun, Electrospun tilapia collagen nanofibers accelerating wound healing via inducing keratinocytes proliferation and differentiation, Colloids Surf., B, 143 (2016) 415-422.

84. J.R. Dias, S. Baptista-Silva, C.M.T. de Oliveira, A. Sousa, A.L. Oliveira, P.J. Bártolo, P.L. Granja, In situ crosslinked electrospun gelatin nanofibers for skin regeneration, Eur. Polym. J., 95 (2017) 161-173.

85. G. Rath, T. Hussain, G. Chauhan, T. Garg, A.K. Goyal, Collagen nanofiber containing silver nanoparticles for improved wound-healing applications, J. Drug Targeting, 24 (2016) 520-529.

86. N. Monteiro, M. Martins, A. Martins, N.A. Fonseca, J.N. Moreira, R.L. Reis, N.M. Neves, Antibacterial activity of chitosan nanofiber meshes with liposomes immobilized releasing gentamicin, Acta Biomater., 18 (2015) 196-205.

87. P. Wutticharoenmongkol, P. Hannirojram, P. Nuthong, Gallic acid-loaded electrospun cellulose acetate nanofibers as potential wound dressing materials, Polym. Adv. Technol., 30 (2019) 1135-1147.

88. S. Selvaraj, N.N. Fathima, Fenugreek incorporated silk fibroin nanofibers-A potential antioxidant scaffold for enhanced wound healing, ACS Appl. Mater. Interfaces, 9 (2017) 5916-5926.

89. E. Mehteroğlu, A.B. Çakmen, B. Aksoy, S. Balcıoğlu, S. Köytepe, B. Ateş, I. Yılmaz, Preparation of hybrid PU/PCL fibers from steviol glycosides via electrospinning as a potential wound dressing materials, J. Appl. Polym. Sci., 137 (2020) 49217.

90. P.P. Mahamuni-Badiger, P.M. Patil, P.R. Patel, M.J. Dhanavade, M.V. Badiger, Y.N. Marathe, R.A. Bohara, Electrospun poly(3hydroxybutyrate-co-3-hydroxyvalerate)/polyethylene oxide (PEO) microfibers reinforced with $\mathrm{ZnO}$ nanocrystals for antibacterial and antibiofilm wound dressing applications, New J. Chem., 44 (2020) 9754-9766.

91. M. Akrami-Hasan-Kohal, L. Tayebi, M. Ghorbani, Curcuminloaded naturally-based nanofibers as active wound dressing mats: morphology, drug release, cell proliferation, and cell adhesion studies, New J. Chem., 44 (2020) 10343-10351.

92. H. Samadian, S. Zamiri, A. Ehterami, S. Farzamfar, A. Vaez, H. Khastar, M. Alam, A. Ai, H. Derakhshankhah, Z. Allahyari, A. Goodarzi, M. Salehi, Electrospun cellulose acetate/gelatin nanofibrous wound dressing containing berberine for diabetic foot ulcer healing: in vitro and in vivo studies, Sci. Rep., 10 (2020) 8312.

93. A. Naeimi, M. Payandeh, A.R. Ghara, F.E. Ghadi, In vivo evaluation of the wound healing properties of bio-nanofiber chitosan/polyvinyl alcohol incorporating honey and Nepeta dschuparensis, Carbohydr. Polym., 240 (2020) 116315.

94. A.Z. Bazmandeh, E.Mirzaei, M. Fadaie, S. Shirian, Y. Ghasemi, Dual spinneret electrospun nanofibrous/gel structure of chitosan-gelatin/chitosan-hyaluronic acid as a wound dressing: In-vitro and in-vivo studies, Int. J. Biol. Macromol., 162 (2020) 359-373. 
95. W.A. Sarhan, H.M.E. Azzazy, I.M. El-Sherbiny, Honey/ chitosan nanofiber wound dressing enriched with Allium sativum and Cleome droserifolia: Enhanced antimicrobial and wound healing activity, ACS Appl. Mater. Interfac., 8 (2016) 6379-6390.

96. S. Homaeigohar, T.Y. Tsai, E.S. Zarie, M. Elbahri, T.H. Young, A.R. Boccaccini, Bovine Serum Albumin (BSA)/ polyacrylonitrile (PAN) biohybrid nanofibers coated with a biomineralized calcium deficient hydroxyapatite (HA) shell for wound dressing, Mater. Sci. Eng. C, 116(2020) 111248.

97. M. Alishahi, M. Khorram, Q. Asgari, F. Davani, F. Goudarzi, A. Emami, A. Arastehfar, K. Zomorodian, Glucantimeloaded electrospun core-shell nanofibers composed of poly(ethylene oxide)/gelatin-poly(vinyl alcohol)/chitosan as dressing for cutaneous leishmaniasis, Int. J. Biol. Macromol., 163 (2020) 288-297.

98. A. Joshi, Z. Xu, Y. Ikegami, K. Yoshida, Y. Sakai, A. Joshi, T. Kaur, Y. Nakao, Y.I. Yamashita, H. Baba, S. Aishima, N. Singh, H. ljima, Exploiting synergistic effect of externally loaded bFGF and endogenous growth factors for accelerated wound healing using heparin functionalized $\mathrm{PCL} /$ gelatin co-spun nanofibrous patches, Chem. Eng. J., 404 (2021) 126518.

99. Y. Hussein, E.M. El-Fakharany, E.A. Kamoun, S.A. Loutfy, R. Amin, T.H. Taha, S.A. Salim, M. Amer, Electrospun PVA/hyaluronic acid/L-arginine nanofibers for wound healing applications: Nanofibers optimization and in vitro bioevaluation, Int. J. Biol. Macromol., 164 (2020) 667-676.

100. R.E. Elsayed, T.M. Madkour, R.A. Azzam, Tailored-design of electrospun nanofiber cellulose acetate/poly(lactic acid) dressing mats loaded with a newly synthesized sulfonamide analog exhibiting superior wound healing, Int. J. Biol. Macromol., 164 (2020) 1984-1999.

101. W. Liu, S. Thomopoulos, Y. Xia, Electrospun nanofibers for regenerative medicine, Adv. Healthcare Mater., 1 (2012) 10 25.

102. X. Wang, B. Ding, B. Li, Biomimetic electrospun nanofibrous structures for tissue engineering, Mater. Today, 16 (2013) 229-241.

103. Y. Zhang, X. Liu, L. Zeng, J. Zhang, J. Zuo, J. Zou, J. Ding, $X$ Chen, Polymer fiber scaffolds for bone and cartilage tissue engineering, Adv. Funct. Mater., 29 (2019) 1903279.

104. T. Yao, M.B. Baker, L. Moroni, Strategies to improve nanofibrous scaffolds for vascular tissue engineering, Nanomaterials, 10 (2020) 887.

105. S. Parham, A.Z. Kharazi, H.R. Bakhsheshi-Rad, H. Ghayour, A.F. Ismail, H. Nur, F. Berto, Electrospun nano-fibers for biomedical and tissue engineering applications: A comprehensive review, Materials, 13 (2020) 2153

106. A. Keirouz, M. Chung, J. Kwon, G. Fortunato, N. Radacsi, 2D and $3 \mathrm{D}$ electrospinning technologies for the fabrication of nanofibrous scaffolds for skin tissue engineering: A review, WIREs Nanomed. Nanobiotechnol., 12 (2020) e01626.

107. X. Xie, Y. Chen, X. Wang, X. Xu, Y. Shen, A. ur Rehman Khan, A. Aldalbahi, A.E. Fetz, G.L. Bowlin, M. El-Newehy, X. Mo, Electrospinning nanofiber scaffolds for soft and hard tissue regeneration, J. Mater. Sci. Technol., 59 (2020) 243-261.

108. W. Lin, M. Chen, T. Qu, J. Li, Y. Man, Three-dimensional electrospun nanofibrous scaffolds for bone tissue engineering, J. Biomed. Mater. Res., 108 (2020) 1311-1321.

109. G.L. Koons, M. Diba, A.G. Mikos, Materials design for bonetissue engineering, Nat. Rev. Mater., 5 (2020) 584-603.

110. J.R. Porter, T.T. Ruckh, K.C. Popat, Bone tissue engineering: A review in bone biomimetics and drug delivery strategies, Biotechnol. Progr., 25 (2009) 1539-1560.
111. L. Roseti, V. Parisi, M. Petretta, C. Cavallo, G. Desando, I. Bartolotti, B. Grigolo, Scaffolds for bone tissue engineering: state of the art and new perspectives, Mater. Sci. Eng. C, 78 (2017) 1246-1262.

112. H. Samadian, S. Farzamfar, A. Vaez, A. Ehterami, A. Bit, M. Alam, A. Goodarzi, G. Darya, M. Salehi, A tailored polylactic acid/polycaprolactone biodegradable and bioactive 3D porous scaffold containing gelatin nanofibers and Taurine for bone regeneration, Sci. Rep., 10 (2020) 13366.

113. K. Ye, D. Liu, H. Kuang, J. Cai, W. Chen, B. Sun, L. Xia, B. Fang, Y. Morsi, X. Mo, Three-dimensional electrospun nanofibrous scaffolds displaying bone morphogenetic protein-2-derived peptides for the promotion of osteogenic differentiation of stem cells and bone regeneration, J. Colloid Interface Sci., 534 (2019) 625-636.

114. Y. Wang, W. Cui, X. Zhao, S. Wen, Y. Sun, J. Han, H. Zhang, Bone remodeling-inspired dual delivery electrospun nanofibers for promoting bone regeneration, Nanoscale, 11 (2019) 60-71.

115. E. Ko, J.S. Lee, H. Kim, S.Y. Yang, D. Yang, K. Yang, J. Lee, J. Shin, H.S. Yang, W. Ryu, S.W. Cho, Electrospun silk fibroin nanofibrous scaffolds with two-stage hydroxyapatite functionalization for enhancing the osteogenic differentiation of human adipose-derived mesenchymal stem cells, ACS Appl. Mater. Interfaces, 10 (2018) 7614-7625.

116. G.P. Awasthi, V.K. Kaliannagounder, B. Maharjan, J.Y. Lee, C.H. Park, C.S. Kim, Albumin-induced exfoliation of molybdenum disulfide nanosheets incorporated polycaprolactone/zein composite nanofibers for bone tissue regeneration, Mater. Sci. Eng. C, 116 (2020) 111162.

117. H. Nekounam, Z. Allahyari, S. Gholizadeh, E. Mirzaei, M.A. Shokrgozar, R. Faridi-Majidi, Simple and robust fabrication and characterization of conductive carbonized nanofibers loaded with gold nanoparticles for bone tissue engineering applications, Mater. Sci. Eng. C, 117 (2020) 111226.

118. C.E. Schmidt, J.B. Leach, Neural tissue engineering: Strategies for repair and regeneration, Annu. Rev. Biomed. Eng., 5 (2003) 293-347.

119. V. Mukhatyar, L. Karumbaiah, J. Yeh, R. Bellamkonda, Tissue engineering strategies designed to realize the endogenous regenerative potential of peripheral nerves, Adv. Mat., 21 (2009) 4670-4679.

120. X. Jiang, S.H. Lim, H.Q. Mao, S.Y. Chew, Current applications and future perspectives of artificial nerve conduits, Exp. Neurol., 223 (2010) 86-101.

121. M. Siemionow, M. Bozkurt, F. Zor, Regeneration and repair of peripheral nerves with different biomaterials: Review, Microsurgery 30 (2010) 574-588

122. C.R. Carvalho, J.M. Oliveira, R.L. Reis, Modern trends for peripheral nerve repair and regeneration: Beyond the hollow nerve guidance conduit, Front. Bioeng. Biotechnol., 7 (2019) 337.

123. J. Scheib, A. Höke, Advances in peripheral nerve regeneration, Nat. Rev. Neurol., 9 (2013) 668-676.

124. J. Xie, M.R. MacEwan, W. Liu, N. Jesuraj, X. Li, D. Hunter, Y. Xia, Nerve guidance conduits based on double-layered scaffolds of electrospun nanofibers for repairing the peripheral nervous system, ACS Appl. Mater. Interfaces, 6 (2014) 9472-9480.

125. J. Wang, L. Tian, L. He, N. Chen, S. Ramakrishna, K.F. So, X. Mo, Lycium barbarum polysaccharide encapsulated Poly lactic-co-glycolic acid Nanofibers: cost effective herba medicine for potential application in peripheral nerve tissue engineering, Sci. Rep., 8 (2018) 8669. 
126. N. Saderi, M. Rajabi, B. Akbari, M. Firouzi, Z. Hassannejad, Fabrication and characterization of gold nanoparticledoped electrospun PCL/chitosan nanofibrous scaffolds for nerve tissue engineering, J. Mater. Sci. Mater. Med., 29 (2018) 134

127. F. Zha, W. Chen, L. Hao, C. Wu, M. Lu, L. Zhang, D. $\mathrm{Yu}$, Electrospun cellulose-based conductive polymer nanofibrous mats: composite scaffolds and their influence on cell behavior with electrical stimulation for nerve tissue engineering, Soft Matter., 16 (2020) 6591-6598.

128. X. Hu, X. Wang, Y. Xu, L. Li, J. Liu, Y. He, Y. Zou, L. Yu, X. Qiu, J. Guo, Electric conductivity on aligned nanofibers facilitates the transdifferentiation of mesenchymal stem cells into schwann cells and regeneration of injured peripheral nerve, Adv. Healthcare Mater., 9 (2020) 1901570.

129. H. Yan, Y. Wang, L. Li, X. Zhou, X. Shi, Y. Wei, P. Zhang, A micropatterned conductive electrospun nanofiber mesh combined with electrical stimulation for synergistically enhancing differentiation of rat neural stem cells, J. Mater Chem. B, 8 (2020) 2673-2688.

130. M. Heidari, S.H. Bahrami, M. Ranjbar-Mohammadi, P.B. Milan, Smart electrospun nanofibers containing PCL/gelatin/ graphene oxide for application in nerve tissue engineering, Mater. Sci. Eng. C, 103 (2019) 109768

131. H. Kwon, W.E. Brown, C.A. Lee, D. Wang, N. Paschos, J.C. Hu, K.A. Athanasiou, Surgical and tissue engineering strategies for articular cartilage and meniscus repair, Nat. Rev. Rheumatol., 15 (2019) 550-570.

132. E.A. Makris, A.H. Gomoll, K.N. Malizos, J.C. Hu, K.A. Athanasiou, Repair and tissue engineering techniques for articular cartilage, Nat. Rev. Rheumatol., 11 (2015) 21-34.

133. M.W. Kessler, D.A. Grande, Tissue engineering and cartilage, Organogenesis, 4 (2008) 28-32.

134. W. Chen, S. Chen, Y. Morsi, H. El-Hamshar, M. El-Newh, C. Fan, $X$. Mo, Superabsorbent 3D scaffold based on electrospun nanofibers for cartilage tissue engineering, ACS Appl. Mater Interfaces, 8 (2016) 24415-24425.

135. G. Nour-Eldeen, M. Abdel-Rasheed, A.M. EL-Rafei, O. Azmy, G.T. El-Bassyouni, Adipose tissue-derived mesenchymal stem cells and chitosan/poly (vinyl alcohol) nanofibrous scaffolds for cartilage tissue engineering, Cell Regen., 9 (2020) 7.
136. X. Liu, S. Song, J. Huang, H. Fu, X. Ning, Y. He, Z. Zhang, HBC-nanofiber hydrogel scaffolds with 3D printed internal microchannels for enhanced cartilage differentiation, J. Mater. Chem. B, 8 (2020) 6115-6127.

137. H.M. Mousa, K.H. Hussein, M.M. Sayed, M.R. El-Aassar, I.M.A. Mohamed, H.H. Kwak, H.M. Woo, A. Abdal-hay, Development of biocompatible tri-layered nanofibers patches with endothelial cells for cardiac tissue engineering, Eur. Polym. J., 129 (2020) 109630.

138. Y. Zhang, Z. Zhang, Y. Wang, Y. Su, M. Chen, 3D myotube guidance on hierarchically organized anisotropic and conductive fibers for skeletal muscle tissue engineering, Mater. Sci. Eng. C, 116 (2020) 111070.

139. S. Wu, R. Zhou, F. Zhou, P.N. Streubel, S. Chen, B. Duan, Electrospun thymosin Beta-4 loaded PLGA/PLA nanofiber/ microfiber hybrid yarns for tendon tissue engineering application, Mater. Sci. Eng. C, 106 (2020) 110268.

140. S. Mohandesnezhad, Y. Pilehvar-Soltanahmadi, E. Alizadeh, A. Goodarzi, S. Davaran, M. Khatamian, N. Zarghami, M. Samiei, M. Aghazadeh, A. Akbarzadeh, In vitro evaluation of Zeolite-nHA blended PCL/PLA nanofibers for dental tissue engineering, Mater. Chem. Phys., 252 (2020) 123152.

141. W. Yao, H. Gu, T. Hong, Y. Wang, S. Chen, X. Mo, W. Li, C. Wang, T. Zhu, S. Lu, A bi-layered tubular scaffold for effective anti-coagulant in vascular tissue engineering, Mater. Des., 194 (2020) 108943.

142. L. Huang, X. Wang, Y. Zhang, Z. Cheng, F. Xue, Y. Guo, Y. Deng, C. Chu, L. Tao, J. Bai, Electrospun Mg/poly(lactic-co-glycolic acid) composite scaffold for urethral reconstruction, J. Mater. Sci., 55 (2020) 13216-13231.

143. N. Forouzideh, S. Nadri, A. Fattahi, E.D. Abdolahinia, M. Habibizadeh, K. Rostamizadeh, A. Baradaran-Rafii, H. Bakhshandeh, Epigallocatechin gallate loaded electrospun silk fibroin scaffold with anti-angiogenic properties for corneal tissue engineering, J. Drug Delivery Sci. Technol., 56 (2020) 101498.

144. ElectrospinTech http://electrospintech.com/espincompanies.html\#.XwOULC2z3Uq (accessed 31 Aug 2020)

145. Polyremedy, https://polyremedy.com (accessed 31 Aug 2020).

146. Nicast, http://nicast.com/avflo/product-description/ (accessed 31 Aug 2020)

147. BioSurfaces Inc., https://www.biosurfaces.us/drugloading-1 (accessed 31 Aug 2020). 